\title{
Acute kidney injury-epidemiology, outcomes and economics
}

\author{
Oleksa Rewa and Sean M. Bagshaw
}

\begin{abstract}
Acute kidney injury (AKI) is a widespread problem of epidemic status. Compelling evidence indicates that the incidence of AKI is rapidly increasing, particularly among hospitalized patients with acute illness and those undergoing major surgery. This increase might be partially attributable to greater recognition of AKI, improved ascertainment in administrative data and greater sensitivity of consensus diagnostic and classification schemes. Other causes could be an ageing population, increasing incidences of cardiovascular disease, diabetes mellitus and chronic kidney disease (CKD), and an expanding characterization of modifiable risk factors, such as sepsis, administration of contrast media and exposure to nephrotoxins. The sequelae of AKI are severe and characterized by increased risk of short-term and long-term mortality, incident CKD and accelerated progression to end-stage renal disease. AKI-associated mortality is decreasing, but remains unacceptably high. Moreover, the absolute number of patients dying as a result of AKI is increasing as the incidence of the disorder increases, and few proven effective preventative or therapeutic interventions exist. Survivors of AKI, particularly those who remain on renal replacement therapy, often have reduced quality of life and consume substantially greater health-care resources than the general population as a result of longer hospitalizations, unplanned intensive care unit admissions and rehospitalizations.
\end{abstract}

Rewa, O. \& Bagshaw, S. M. Nat. Rev. Nephrol. 10, 193-207 (2014); published online 21 January 2014; doi:10.1038/nrneph.2013.282

\section{Introduction}

Acute kidney injury (AKI, previously termed acute renal failure) is a common, increasingly encountered complication among patients hospitalized for acute illness. ${ }^{1-3}$ The disorder is generally characterized by an abrupt deterioration in kidney function that disrupts metabolic, electrolyte and fluid homeostasis over a period of hours to days. The spectrum of AKI is broad, ranging from small changes in the levels of biochemical markers of kidney function to overt kidney failure requiring initiation of renal replacement therapy (RRT).

The clinical importance of AKI is exemplified by data showing a consistent association with increased longterm risk of poor outcomes, including death, incident chronic kidney disease (CKD), and greater utilization of health resources. ${ }^{4}$ Compelling evidence from observational studies indicates that the incidence of AKI is increasing, and although mortality is concomitantly decreasing, more patients are ultimately suffering the long-term sequelae of AKI. ${ }^{5,6}$ The reality is even more alarming considering the paucity of effective interventions to prevent $\mathrm{AKI}$ in at-risk patients or to mitigate established kidney damage, other than supportive measures, such as initiation of RRT. ${ }^{7}$

These observations strongly reinforce the global importance of increasing awareness of the poor outcomes

\section{Competing interests}

S. M. Bagshaw declares associations with the following companies: Alere Inc., Baxter Inc., Gambro Inc. See the article online for full details of the relationships. 0 . Rewa declares no competing interests. and profound economic impact that AKI might have on patients, communities and health systems. In 2013, the World Kidney Day Steering Committee focused on AKI, directing awareness to its impact and calling for campaigns to promote the prevention and prompt identification of AKI in patients at risk as well as the implementation of evidence-informed protocols and policies to mitigate its impact. ${ }^{8}$ In this Review we provide an overview of the evolving epidemiology, outcomes and economic implications of AKI.

\section{Definitions of AKI}

A wide array of operational definitions of AKI exists. For example, a systematic review of clinical studies focusing on cardiac surgery reported that $>35$ different definitions were used for AKI diagnosis. ${ }^{9}$ This lack of standardization has created huge challenges for the optimal estimation of the burden of illness and outcomes attributable to the disorder (Figure 1). The RIFLE and AKIN consensus criteria were developed in response to the growing need for consistency and standardization in the diagnostic classification of AKI. ${ }^{10-12}$ These classification schemes have since been combined in the KDIGO Clinical Practice Guideline for AKI. ${ }^{13}$ The KDIGO AKI criteria use the conventional surrogates of kidney function, serum creatinine level and urine output, to define the presence and severity of kidney injury. ${ }^{13}$ Numerous studies that evaluated these classification schemes (or their previous iterations) have shown gradient-response relationships between severity of AKI and risk of poor outcomes. ${ }^{14}$ 


\section{Key points}

- Acute kidney injury (AKI) occurs in an estimated one in five adults and one in three children hospitalized with acute illness; the incidence of AKI is increasing

- Subclinical AKI, defined as elevation in levels of kidney damage biomarkers not fulfilling the conventional criteria for AKI, has characterized a subgroup of patients with increased risk of poor outcome

- Bedside clinical information systems can enable real-time automated electronic alerting for patients at risk of AKI or who develop early AKI; these systems can be integrated with evidence-based decision support tools

- The mortality associated with AKI remains unacceptably high, and increasing severity correlates with increasing mortality, the highest of which is among patients with overt kidney failure requiring renal replacement therapy

- Reduced health-related quality of life and incident disability are increasingly recognized as important patient-centred outcomes following acute illness complicated by AKI

- AKI is now recognized as an important risk factor for nonrecovery of kidney function, incident chronic kidney disease, and accelerated progression to end-stage renal disease resuscitation and accumulation in acute illness. ${ }^{23-25}$ Adjustment for fluid balance in critically ill patients at risk of AKI improves the diagnostic classification and identifies a previously 'unrecognized' subgroup of patients at higher risk of mortality compared to those without AKI. ${ }^{23}$

Numerous studies, in particular analyses of large observational datasets from administrative or registry databases, have omitted the urine output contribution in the definition of AKI. However, in the past few years, an association between episodes of oliguria and greater risks of worsening AKI, need for RRT and death has been confirmed. ${ }^{26-29}$ Further data suggest that the current urine output threshold for the diagnosis of AKI $(0.5 \mathrm{ml} / \mathrm{kg} / \mathrm{h}$ for $6 \mathrm{~h}$ ) is too sensitive and is not prognostically aligned with the serum creatinine criteria. ${ }^{30}$ These findings have led to a call to lower the urine output threshold for AKI diagnosis to $0.3 \mathrm{ml} / \mathrm{kg} / \mathrm{h}$ for $6 \mathrm{~h}$ to better correlate with worsening kidney function, need for RRT and death. ${ }^{30}$

The current classification schemes (RIFLE, AKIN and KDIGO) do not integrate novel kidney damage biomarkers (for example, neutrophil gelatinase associated lipocalin [NGAL], kidney injury molecule-1 [KIM-1], and interleukin-18 [IL-18]) for early diagnosis, severity staging and predicting prognosis of AKI. ${ }^{31,32}$ Although these novel biomarkers have been reported to correlate with and predict worse outcomes of AKI, study findings are not consistent. ${ }^{33-37}$ The concept of subclinical AKI has emerged from studies that characterized the association between kidney damage biomarkers and outcomes. ${ }^{38,39}$ A subgroup of patients have been identified with elevated levels of these biomarkers (for example, NGAL) who do not fulfil the conventional consensus criteria for AKI but have increased risks of RRT initiation and death compared to those without elevation of these biomarkers. ${ }^{35,40}$ However, the reported diagnostic performance of many of these biomarkers varies as a result of issues such as limitations in study design and methodology, differing patient populations, aetiology of AKI, timing of measurement relative to injury, specific factors related to individual biomarkers, and the selected thresholds for
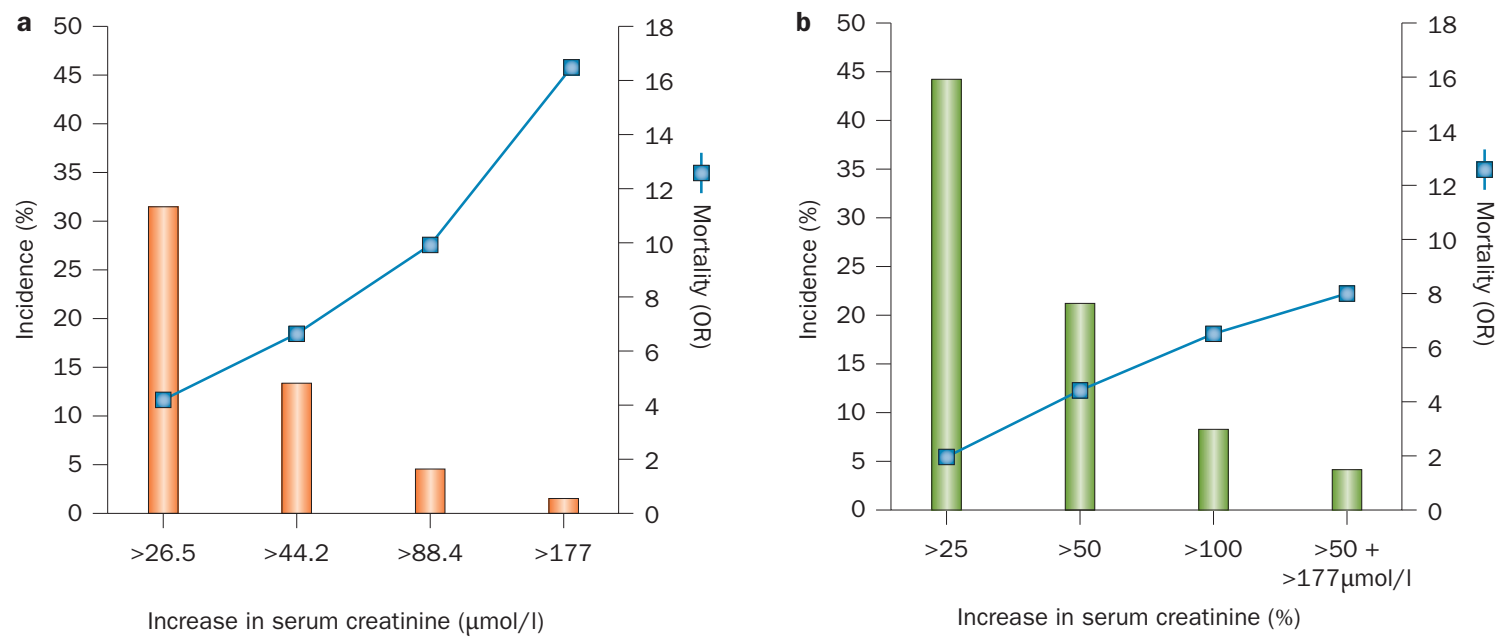

Figure 1 | Association between the incidence and mortality for acute kidney injury when assessed by a $\mid$ absolute changes in serum creatinine levels and $\mathbf{b} \mid$ changes in serum creatinine levels relative to baseline. Data obtained from Chertow et al. ${ }^{52}$ 
discriminating kidney damage and diagnosis of AKI. ${ }^{31,32}$ This variability has generated challenges for their routine translation into clinical practice.

The development of consensus definitions for AKI was a monumental step towards improving the scientific understanding of the disorder. The role of these consensus definitions at the bedside to guide the clinical care of patients is still being evaluated and is not precisely defined. ${ }^{41}$ Future refinement of the classification schemes is likely and is expected to involve investigation of modifications to the urine output criteria and the role of kidney damage biomarkers, integration of metrics of fluid balance and evaluation of time-averaged changes in serum creatinine levels. ${ }^{42}$

Hospitalized patients are increasingly monitored using electronic medical records and bedside clinical information systems. These systems can be automated to provide real-time electronic alerts to clinicians for patients considered to be at risk of AKI or who develop the diagnostic criteria for AKI. They can also be integrated with evidence-based decision support tools. ${ }^{43}$ Use of such systems might provide a greater opportunity for clinicians to avoid or modify reversible risk factors (such as nephrotoxin exposure) compared with conventional recognition of AKI (that is, review of clinical data by a clinician during rounds). ${ }^{41,43,44}$

\section{Epidemiology of AKI \\ Developed countries}

A systematic review of 312 cohort studies, which included 49 million patients (mostly from high-income countries), found that AKI occurred in one in five adults and one in three children hospitalized with acute illness. ${ }^{2}$ In a large US population $(n=3,787,410)$, the communitybased incidence of nonRRT-requiring AKI (defined using relative changes in serum creatinine levels) and RRT-requiring AKI (defined using integrated administrative data) was estimated at 384.1 and 24.4 per 100,000 persons-years, respectively. ${ }^{45}$ Between 1996 and 2003, the incidences of nonRRT-requiring and RRT-requiring AKI in this population increased significantly from 322.7 to 522.4 per 100,000 person-years $(38 \%)$ and from 19.5 to 29.5 per 100,000 person-years $(33 \%)$, respectively. The occurrence of AKI was most common among elderly, male and black patients. The observed incidence of nonRRT-requiring AKI in this study was much higher than prior estimates from studies that primarily used administrative claims data to ascertain AKI status; however, all of these studies reported significant increases in the incidence of AKI over time. ${ }^{5,6,46,47}$ In a large retrospective cohort study ( $n=49,518)$, approximately $1 \%$ of hospitalized patients had evidence of 'subacute' kidney injury, defined as relative changes in serum creatinine fulfilling the RIFLE classification for AKI but occurring over the duration of hospitalization rather than within 7 days. ${ }^{48}$ Subacute kidney injury was independently associated with increased hospital mortality.

The use of administrative claims data for identifying AKI has shown poor sensitivity and might substantially underestimate the true incidence of AKI. ${ }^{46,49,50}$ In a large
Scottish cohort $(n=523,390)$, the population-based incidence of AKI, defined using the RIFLE criteria, was 1,811 per million population-considerably higher than previously thought. ${ }^{51}$ Several plausible explanations for the growing secular trends in AKI incidence exist, including increased sensitivity of diagnostic coding in administrative data, ${ }^{50}$ confounding by 'coding creep' 6 (that is, increased use of administrative codes for AKI) and increased sensitivity of consensus diagnostic criteria. ${ }^{51}$ However, the available evidence strongly suggest that the true incidence of AKI is growing. These observations are reinforced by data showing that sensitive definitions of AKI incorporating small relative changes in serum creatinine levels correspond to marked increased risks of poor outcomes. ${ }^{52,53}$

In the USA, the incidence of hospital-acquired AKI increased from $4.9 \%$ in 1979 to $7.2 \%$ in $1996 .{ }^{54,55}$ In a large Australian single-centre, hospital-based cohort study $(n=20,126)$, the incidence of AKI (defined using RIFLE criteria) was $18 \%$ and worsening RIFLE category correlated with near-linear increases in mortality. ${ }^{56}$ Similar secular trends have also been noted for severe AKI requiring RRT. For example, a US study that used data from the Nationwide Inpatient Sample dataset reported a $10 \%$ annual increase in the incidence of AKI requiring RRT from 222 cases per million-person years in 2000 to 533 cases per million-person years in $2009 .{ }^{57}$ In a population-based study in Ontario, Canada, which included 552,672 patients, the incidence of RRT utilization after elective surgery increased significantly from $0.2 \%$ in 1995 to $0.6 \%$ in $2009 .{ }^{58}$ This increase was the result of increased utilization of RRT after cardiac and major vascular surgeries.

Several large cohort studies have focused on describing the incidence of AKI in intensive care settings. ${ }^{16,59-70}$ In a large multinational study, the incidence of AKI among patients admitted to intensive care units (ICUs) was only $5.7 \%{ }^{68}$ However, this study used a definition of AKI (that is, urine output $<200 \mathrm{ml}$ in $12 \mathrm{~h}$; serum urea $>30 \mathrm{mmol} / \mathrm{l}$ or initiation of RRT) that was intended to identify only those patients who were most severely affected (of whom approximately $70 \%$ required RRT). Subsequent cohort studies that integrated consensus definitions of AKI and used administrative databases reported AKI incidences in the ICU setting of $16-39 \% ;{ }^{61,67}$ however, these studies often omitted or modified urine output criteria, used estimated reference serum creatinine levels or ascertained AKI status within $24 \mathrm{~h}$ of ICU admission. Two large cohort studies of critically ill patients described incidence rates of AKI of $65-67 \% .{ }^{64,69}$ The marked increased incidence in these studies is likely attributable to application of consensus AKI criteria as intended, with inclusion of the urine output criteria. ${ }^{10,11,13}$ The population-based incidence of RRT utilization among critically ill patients with AKI is 11-19 cases per 100,000 , which represents $4-8 \%$ of all critically ill patients. ${ }^{15,68,70,71}$ Similar to population and hospital-based studies, secular trends of growing AKI incidence in ICU settings have been described. In a cohort that included more than 90,000 patients admitted to ICUs in 20 centres across Australia and New Zealand over a 10-year period, 


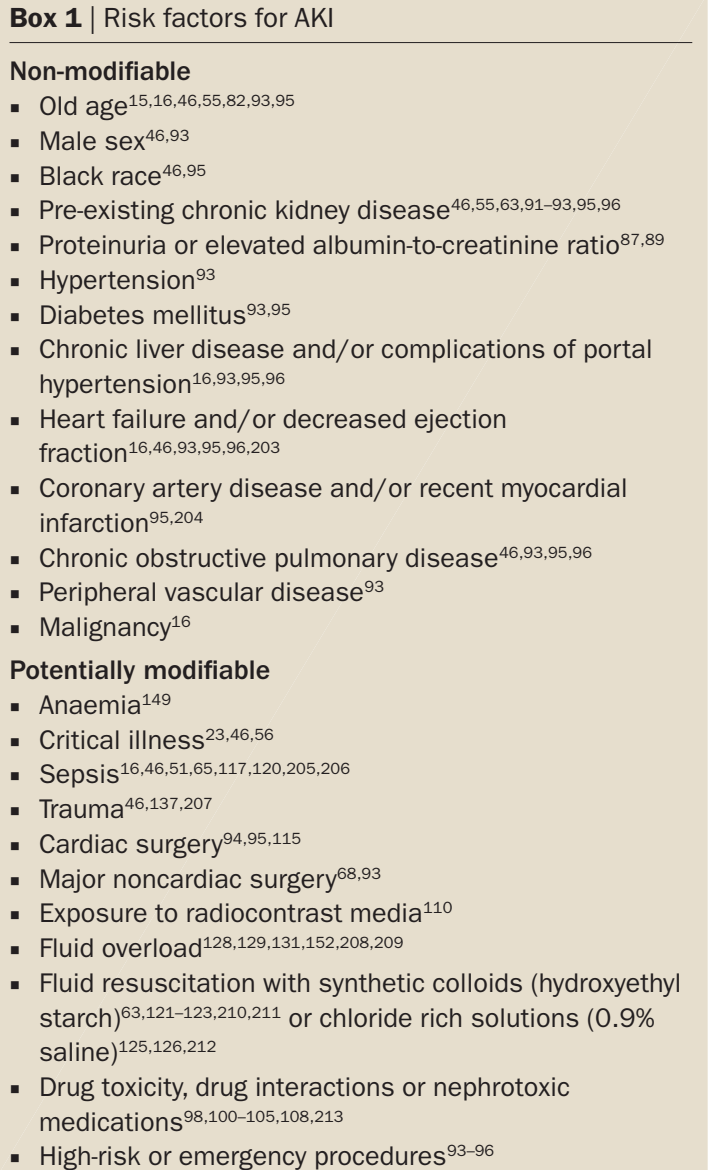

the incidence of AKI increased by $2.8 \%$ per year, whereas associated mortality decreased by $3.4 \%$ per year. ${ }^{60}$

\section{Developing countries}

Although a substantial majority of data on the epidemiology of AKI are from developed countries, ${ }^{2} \mathrm{AKI}$ is increasingly recognized as an important contributor to morbidity, mortality and economic loss worldwide, particularly in developing countries. ${ }^{8}$ One of the challenges associated with estimating the epidemiology of AKI in developing regions is that the available data are often from small, single-centre studies with low methodological quality and limited generalizability. However, these contributions still provide important indications of the broader burden of AKI and serve to focus attention on the disorder.

In general, AKI might be more likely to occur in children and healthy adults in developing countries than in developed countries because of a host of socioeconomic and environmental influences. ${ }^{72}$ Factors contributing to AKI such as infectious diseases (that is, tropical febrile illnesses such as diarrhoea, leptospirosis, malaria and dengue fever), envenoming (as a result of snake, spider or insect bites and/or stings), and obstetrical complications are described far more commonly in studies from developing countries than in those from developed countries. ${ }^{73-79}$ Importantly, in large metropolitan regions in developing countries, the clinical profile of patients at risk of AKI, or in whom AKI occurs, might be very similar to that encountered in developed countries. ${ }^{75,80}$ Failure to measure kidney function among patients at increased risk of AKI is associated with a missed opportunity to intervene and mitigate worsening kidney function and also contributes to gross underestimation of the scope of the problem in developing countries. ${ }^{81}$ These observations further reinforce the importance of initiatives to raise awareness of AKI, such as those promoted by World Kidney Day in $2013 .{ }^{8}$

\section{Factors associated with AKI}

\section{Extremes of age}

A wide array of patient-specific and context-specific factors can modify the risk of AKI. Elderly and very young patients are particularly susceptible to the disorder. Although older age has consistently been shown to increase the risk of AKI, ${ }^{15,16,45,82,83}$ elderly patients with AKI are far less likely to receive RRT than are younger patients. ${ }^{45,84,85}$ Hospitalized children are also at increased risk; up to $50 \%$ of acutely ill children develop AKI, most commonly in association with major surgery and/or sepsis. ${ }^{86}$

\section{Proteinuria}

Pre-existing proteinuria is a risk factor for development of AKI among hospitalized patients. ${ }^{87}$ In patients with proteinuria and eGFR $>60 \mathrm{ml} / \mathrm{min} / 1.73 \mathrm{~m}^{2}$, the adjusted risk of AKI was 4.4-fold higher than in those with no proteinura ${ }^{87} \mathrm{~A}$ similar increased risk of AKI associated with elevated urine albumin-to-creatinine ratio was further increased by declining eGFR ${ }^{88}$ In a large cohort of patients undergoing cardiac surgery, increased urine albumin-to-creatinine ratio independently predicted post-operative AKI (as defined by the AKIN classification) and improved clinical risk prediction. Abnormally elevated urine albumin-to-creatinine ratio was also associated with increased dialysis risk, mortality and prolonged ICU and hospital stays. ${ }^{89}$

\section{Comorbid diseases}

Overt CKD is a recognized risk factor for death, cardiovascular events and hospitalizations ${ }^{90}$ and is also an independent risk factor for development of AKI, nonrecovery of renal function and progression to end-stage renal disease (ESRD)..$^{91,92} \mathrm{CKD}$ is one of the strongest predictors of AKI, as evidenced by its integration into numerous clinical practice guidelines and risk prediction scores for development of post-procedural AKI and need for RRT. ${ }^{93-97}$ Nonrenal comorbid diseases also modify the risk of AKI. ${ }^{15,16}$ Diabetes mellitus, hypertension, cardiovascular disease (that is, coronary artery disease and heart failure), peripheral vascular disease, chronic liver disease (that is, cirrhosis and portal hypertension), and chronic obstructive pulmonary disease have been implicated as important risk factors for development of AKI (Box 1). ${ }^{93-97}$

\section{Exposure to nephrotoxins}

Population-based studies have shown an increased risk of hospitalization-requiring AKI following initiation 


\begin{tabular}{|c|c|c|c|c|c|}
\hline Study & Design & $\begin{array}{l}\text { Population } \\
\text { (n) }\end{array}$ & Medications & $\begin{array}{l}\text { Definition } \\
\text { of } \mathrm{AKI}\end{array}$ & Outcome \\
\hline Dormuth et al. ${ }^{100}$ & $\begin{array}{l}\text { Multicentre, } \\
\text { nested, } \\
\text { case-controlled }\end{array}$ & $\begin{array}{l}\text { Ambulatory, } \\
\text { aged } \geq 40 \text { years, } \\
\text { new statin users } \\
(2,067,639)\end{array}$ & High potency statins & $\begin{array}{l}\text { Diagnostic } \\
\text { codes }\end{array}$ & $\begin{array}{l}\text { AKI in patients without CKD: } \\
\text { RR } 1.34(95 \% \mathrm{Cl} 1.25-1.43) \\
\text { AKI in patients with CKD: } \\
\text { RR } 1.10 \text { (95\% CI 0.99-1.23) }\end{array}$ \\
\hline Leonard et al. ${ }^{101}$ & $\begin{array}{l}\text { Nested, } \\
\text { case-controlled }\end{array}$ & $\begin{array}{l}\text { Ambulatory } \\
(1,351,832)\end{array}$ & $\begin{array}{l}\text { Proton pump } \\
\text { inhibitors }\end{array}$ & $\begin{array}{l}\text { Diagnostic } \\
\text { codes }\end{array}$ & $\begin{array}{l}\text { Acute interstitial nephritis: } \\
\text { adjusted OR } 3.2 \text { (95\% Cl } \\
0.8-12.8) \\
\text { AKI: adjusted OR } 1.05 \text { (95\% Cl } \\
0.97-1.14)\end{array}$ \\
\hline Schneider et al. ${ }^{98}$ & $\begin{array}{l}\text { Nested, } \\
\text { case-controlled }\end{array}$ & $\begin{array}{l}\text { Mixed hospital, } \\
\text { aged }>65 \text { years } \\
(121,722)\end{array}$ & $\begin{array}{l}\text { Nonsteroidal } \\
\text { anti-inflammatories } \\
\text { (including } \\
\text { cyclooxygenase } 2 \\
\text { inhibitors) }\end{array}$ & $\begin{array}{l}\text { ICD-9-CM } \\
\text { within } 30 \text { days } \\
\text { of treatment } \\
\text { initiation }\end{array}$ & $\begin{array}{l}\text { AKI: adjusted RR } 2.1 \text { (95\% Cl } \\
1.6-2.6)\end{array}$ \\
\hline Wikman et al. ${ }^{103}$ & $\begin{array}{l}\text { Prospective } \\
\text { cohort }\end{array}$ & $\begin{array}{l}\text { Ambulatory, HIV } \\
\text { positive ( } 271)\end{array}$ & $\begin{array}{l}\text { Highly active } \\
\text { antiretroviral therapy }\end{array}$ & RIFLE criteria & $\begin{array}{l}\text { Incidence of AKI } 10 \% \text { ( } 7 \text { cases } \\
\text { per } 100 \text { patient years) }\end{array}$ \\
\hline Sorli et al. ${ }^{102}$ & $\begin{array}{l}\text { Single-centre, } \\
\text { prospective } \\
\text { cohort }\end{array}$ & Mixed ICU (102) & CMS & RIFLE criteria & $\begin{array}{l}\text { Incidence of AKI } 25.5 \% \text { at } \\
7 \text { days; } 49.0 \% \text { at end of } \\
\text { treatment } \\
\uparrow \text { Trough CMS plasma levels } \\
\text { associated with } \uparrow \text { risk of AKI }\end{array}$ \\
\hline Bird et al. ${ }^{99}$ & $\begin{array}{l}\text { Nested, } \\
\text { retrospective } \\
\text { cohort }\end{array}$ & $\begin{array}{l}\text { Mixed hospital, } \\
\text { males aged } \\
40-85 \text { years } \\
(13,943)\end{array}$ & $\begin{array}{l}\text { Fluoroquinolones } \\
\text { (current use) }\end{array}$ & ICD-9-CM & $\begin{array}{l}\text { Fluoroquinolones alone: RR of } \\
\text { AKI } 2.2(95 \% \mathrm{CI} 1.7-2.7) \\
\text { Fluoroquinolones plus renin- } \\
\text { angiotensin system blockers: } \\
\text { RR of AKI } 4.5(95 \% \mathrm{Cl} 2.8-7.0)\end{array}$ \\
\hline Zappitelli et al. ${ }^{106}$ & $\begin{array}{l}\text { Single-centre, } \\
\text { retrospective } \\
\text { cohort }\end{array}$ & $\begin{array}{l}\text { Hospitalized } \\
\text { children not in } \\
\text { the ICU (557) }\end{array}$ & Aminoglycosides & $\begin{array}{l}\text { Paediatric } \\
\text { RIFLE criteria }\end{array}$ & $\begin{array}{l}\text { Incidence of } \mathrm{AKI} 33 \% \\
\mathrm{AKI} \text { associated with } \uparrow \text { length of } \\
\text { hospital stay and health-care } \\
\text { costs }\end{array}$ \\
\hline Zhao et al. ${ }^{104}$ & $\begin{array}{l}\text { Multicentre, } \\
\text { retrospective } \\
\text { cohort }\end{array}$ & $\begin{array}{l}\text { Ambulatory, } \\
\text { aged }>66 \text { years, } \\
\text { new fibrate user } \\
(19,072)\end{array}$ & Fibrate & $\begin{array}{l}\text { Diagnostic } \\
\text { coding }\end{array}$ & $\begin{array}{l}\uparrow \mathrm{SCr} \text { : adjusted OR } 2.4(95 \% \mathrm{Cl} \\
1.7-3.3) \\
\text { Nephrologist consultation: } \\
\text { adjusted OR } 1.3 \text { (95\% 1.0-1.6) } \\
\text { No } \uparrow \text { risk of dialysis-requiring AKI }\end{array}$ \\
\hline Ramirez et al. ${ }^{108}$ & $\begin{array}{l}\text { Single-centre, } \\
\text { prospective } \\
\text { chort }\end{array}$ & $\begin{array}{l}\text { Mixed hospital } \\
(179)\end{array}$ & Vancomycin & RIFLE criteria & $\begin{array}{l}\uparrow \text { Trough levels of serum } \\
\text { vancomycin and other } \\
\text { nephrotoxins associated with } \\
\uparrow \text { risk of AKI }\end{array}$ \\
\hline $\begin{array}{l}\text { Centers for } \\
\text { Disease Control } \\
\text { and Prevention }{ }^{214}\end{array}$ & Case series & Ambulatory (16) & $\begin{array}{l}\text { Synthetic } \\
\text { cannabinoids }\end{array}$ & Not specified & $\begin{array}{l}\text { Clustered cases, recent use } \\
\text { associated with AKI and need } \\
\text { for renal replacement therapy }\end{array}$ \\
\hline Radaelli et al. ${ }^{213}$ & $\begin{array}{l}\text { Single-centre, } \\
\text { retrospective } \\
\text { cohort }\end{array}$ & $\begin{array}{l}\text { Cardiac surgery } \\
(3,139)\end{array}$ & $\begin{array}{l}\text { Angiotensin- } \\
\text { converting-enzyme } \\
\text { inhibitors }\end{array}$ & $\begin{array}{l}\text { Increase in } \mathrm{SCr} \\
\text { level of } 50 \% \text { or } \\
44 \mu \mathrm{mol} / \mathrm{I} \text { in } \\
\text { hospital }\end{array}$ & $\begin{array}{l}\text { AKI: OR } 1.23(95 \% \mathrm{Cl} \\
1.01-1.73)\end{array}$ \\
\hline
\end{tabular}

Abbreviations: AKI, acute kidney injury; CMS, colistin methanesulfonate sodium; ICD-9-CM, International Classification of Diseases—9 $9^{\text {th }}$ Revision-Clinical Modification; ICU, intensive care unit; OR, odds ratio; RIFLE, risk, injury, failure, loss, end-stage renal disease; RR, relative risk; SCr, serum creatinine.

of or exposure to commonly prescribed medications, including high potency statins, proton pump inhibitors, non-steroidal anti-inflammatory drugs, fluoroquinolones, fibrates and highly active anti-retroviral therapy (Table 1). ${ }^{98-104}$ Similarly, AKI is increasingly associated with adverse drug interactions, toxicity, inappropriate prescriptions, failure of clinicians to adjust for kidney function when calculating dosages in at-risk patients, and continued exposure to nephrotoxins during AKI. ${ }^{105,106}$ Worsening AKI and hypotension are the most common, potentially avoidable, adverse drug reactions, with angiotensin-converting-enzyme inhibitors and antithrombotics commonly implicated. ${ }^{105}$ Hospitalized patients, particularly those in ICUs, are often exposed to multiple concurrent nephrotoxins. ${ }^{102,103,107-109}$ Antimicrobials are common sources of avoidable nephrotoxicity $55,68,99,102,106,108,109$ and exposure to contrast media is also frequently associated with AKI in hospitalized patients. ${ }^{55}$ In a single-centre study of critically ill patients admitted to ICU who underwent contrast-enhanced radiography examination, contrast-induced AKI developed in $16.3 \%$ of the 787 participants and was associated with higher use of RRT and significantly increased 28-day mortality (adjusted OR 2.7, 95\% CI 1.4-5.5). ${ }^{110}$ 


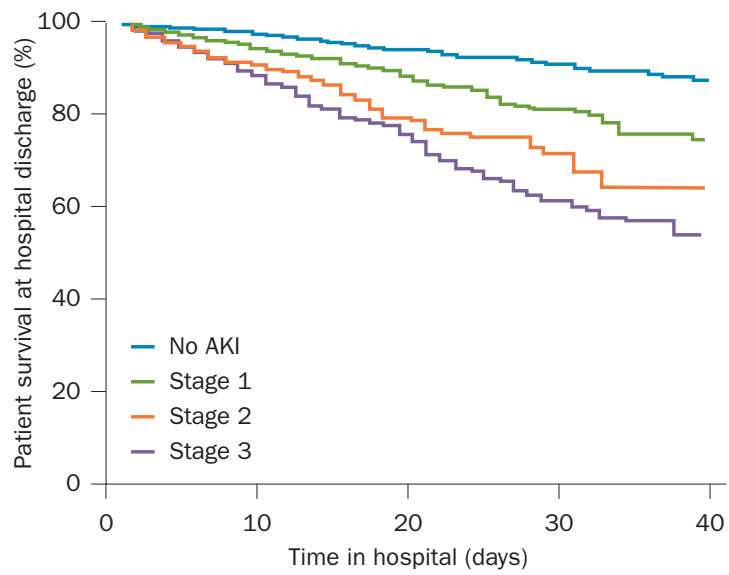

Figure 2 | Kaplan-Meier graph for hospital survival, stratified by KDIGO stages of acute kidney injury. Reproduced with permission from Oxford University Press @ W Wang, H. E. et al. Comparison of absolute serum creatinine changes versus Kidney Disease: Improving Global Outcomes consensus definitions for characterizing stages of acute kidney injury. Nephrol. Dial. Transplant. 28, 1447-1454 (2013).

\section{Major surgery}

AKI after major non-cardiac surgery is uncommon; however, its incidence is modified by the burden of baseline susceptibilities and perioperative factors. ${ }^{111}$ In a prospective, single-centre cohort of patients undergoing major non-cardiac surgery $(n=15,102)$, AKI (defined as creatinine clearance $<50 \mathrm{ml} / \mathrm{min}$ in the first 7 days after surgery) occurred in $0.8 \%$ of participants and was associated with increased mortality at 30 days, 60 days and 1 year. ${ }^{111}$ Perioperative risk factors included older age, higher BMI, comorbid disease, and high-risk or emergency surgeries. In addition, perioperative modifiers included total vasopressor dose, use of vasopressor infusion and diuretic infusion. Among those patients who required temporary support in ICU after surgery, AKI occurred in $9.6 \%$ and resulted in prolonged ICU and hospital stays and higher mortality. In a study that used a US database of 152,244 operative procedures to derive and validate a clinical risk score for AKI (defined as a serum creatinine level $>177 \mu \mathrm{mol} / \mathrm{l}$ or need for RRT within 30 days of surgery), AKI occurred in 1\% of patients and increasing clinical risk score correlated with greater risk of AKI. Patients who had more than five risk factors had a $9 \%$ incidence of AKI and a significantly increased risk of 30-day mortality. ${ }^{93}$

The estimated incidence of AKI (defined using RIFLE or KDIGO criteria or as a $50 \%$ increase in serum creatinine levels from baseline) in patients undergoing cardiac surgery is $11-30 \% .{ }^{112-115}$ Severe AKI requiring RRT occurs in an estimated $1-2 \%$ of these patients. ${ }^{116}$ Numerous studies have derived clinical risk scores of predictors of AKI after cardiac surgery (Box 1). ${ }^{94}$ The strongest predictors of post-operative AKI among clinical risk scores are baseline kidney function and CKD status. ${ }^{95,96}$ Patients with decreases in serum creatinine levels from baseline immediately after surgery were less likely to develop AKI compared to those whose serum creatinine levels increased after surgery. ${ }^{112}$

\section{Sepsis}

In ICUs, AKI occurs most commonly in association with sepsis and is associated with a marked increase in risk of adverse outcomes. ${ }^{62,64,68,117,118}$ A multicentre cohort study found that $64.4 \%$ of critically ill patients with septic shock $(n=4,532)$ developed AKI within $24 \mathrm{~h}$ of ICU admission. ${ }^{119}$ Delay in administration of appropriate antimicrobial therapy after the onset of hypotension was associated with increased risk of AKI. In a multicentre cohort of 33,375 patients admitted to ICUs with a sepsisrelated diagnosis, $42.1 \%$ had early AKI as defined by the RIFLE criteria. ${ }^{117}$ Sepsis is a known precipitating factor for AKI and the development of AKI further predisposes to episodes of sepsis. ${ }^{120}$ Higher RRT use and risk of death has been reported in patients with sepsis occurring after AKI compared with patients without sepsis. ${ }^{120}$

\section{Fluid resuscitation and overload}

Randomized trials of fluid resuscitation using the synthetic colloid hydroxyethyl starch compared with crystalloids have shown higher risk of AKI and RRT use, in particular in patients with sepsis. ${ }^{121-123}$ Administration of chloride-rich solutions (that is, $0.9 \%$ saline) compared with balanced crystalloid solutions are also associated with increased risk of AKI and greater use of RRT in surgical and critically ill patients. ${ }^{124-126}$ Chloride loading might result in deleterious changes in renal haemodynamics and contribute to excess fluid retention. ${ }^{127}$

Fluid overload is increasingly associated with AKI. ${ }^{23,128,129}$ Numerous mechanisms might contribute to the adverse renal consequences of fluid overload, including increased systemic venous pressure, renalspecific parenchymal oedema, intra-abdominal hypertension, and the physiological impact of interventions to treat fluid overload (that is, mechanical ventilation and diuretic therapy). Fluid overload in critically ill patients with AKI has consistently been associated with increased mortality in observational studies. ${ }^{129-131}$

\section{Outcomes of AKI Mortality}

The risk of mortality associated with AKI is unequivocal and consistent across numerous clinical contexts, including acute myocardial infarction, ${ }^{132-134}$ acute decompensated heart failure, ${ }^{135}$ major non-cardiac ${ }^{93,136}$ and cardiac surgeries, ${ }^{53}$ and critical illness. ${ }^{61,67-69,71}$ Despite secular trends in demographic transition characterized by an ageing population, greater prevalence of comorbid illness, higher illness severity and higher intensity of support, AKI-associated mortality is decreasing. 2,5,6,60 However, this mortality remains unacceptably high. The estimated unadjusted mortality associated with an episode of AKI was recently estimated at $23.9 \%$ in adults and $13.8 \%$ in children. ${ }^{2}$

Increasing severity of AKI correlates with increasing mortality, which is highest in patients with overt kidney failure requiring RRT (Figure 2). ${ }^{15,56,61,68,69,71}$ The adjusted risk of in-hospital mortality shows near linear increases with worsening severity of $\mathrm{AKI}^{56}$ and this relationship 


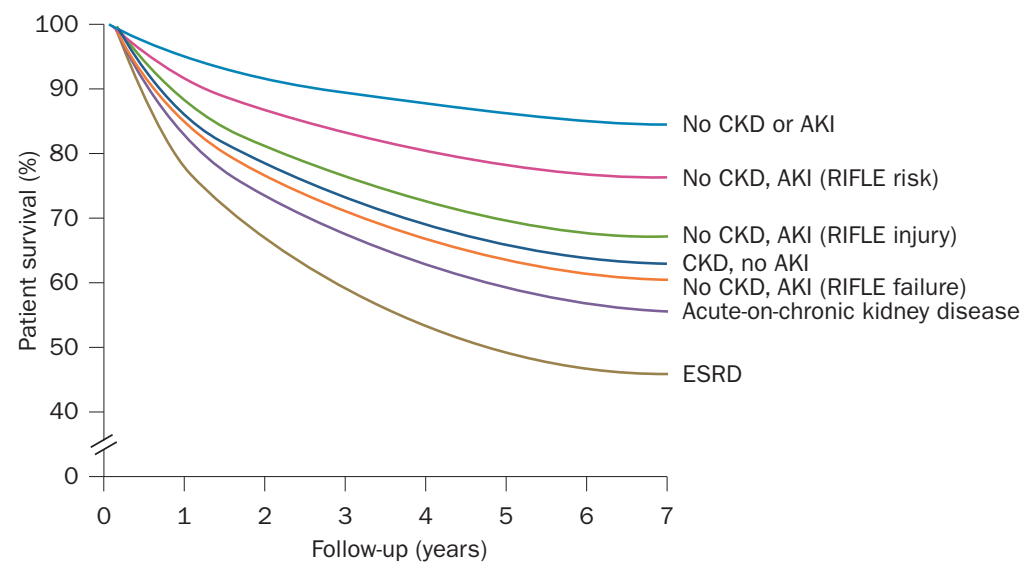

Figure 3 | Long-term survival stratified by CKD and AKI. Cox proportional hazard model for long-term survival of patients alive at hospital discharge, stratified by severity of AKI for patients without CKD (no AKI and RIFLE risk, injury, and failure groups) and by occurrence of AKI for patients with CKD (no AKI and acute-on-chronic kidney disease groups). Abbreviations: AKI, acute kidney injury; CKD, chronic kidney disease; ESRD, end-stage renal disease; RIFLE, risk, injury, failure, loss, end-stage renal disease. Reproduced with permission from Nature Publishing Group $(\odot$ Wu, V. C. et al. Kidney Int. 80, 1222-1230 (2011).

is universally evident across specific settings, such as contrast-induced nephropathy, cardiac surgery, major trauma, sepsis and critical illness. ${ }^{67,69,70,115,137}$ A multicentre, population-based cohort study of 2,901 patients with nonRRT-requiring AKI (defined according to RIFLE criteria) in Finnish ICUs reported in-hospital and 90 -day mortality of $25.6 \%$ and $33.7 \%$, respectively. ${ }^{63}$ Patients who survive an acute hospitalization associated with AKI remain at excess increased risk of mortality long after the inciting event compared with those without AKI. ${ }^{138-140}$ Among US patients who survived for at least 90 days after discharge from an acute-care hospitalization ( $n=864,933)$, long-term mortality was $29.8 \%$ in those with AKI compared with only $16.1 \%$ in those who did not have AKI (adjusted relative risk 1.41, 95\% CI 1.39-1.43). ${ }^{138}$ Similarly, in a Canadian population-based cohort of critically ill patients with AKI who did not require dialysis $(n=41,327)$, the risk of long-term mortality was increased compared with a matched cohort of critically ill patients without AKI (adjusted hazard ratio 1.10; 95\% CI 1.07-1.13). ${ }^{139}$

AKI-associated mortality is highest among patients with severe AKI requiring RRT, particularly in the setting of critical illness, with estimated in-hospital mortality approaching $60 \% .{ }^{15,68,141}$ Emerging data, however, suggest that the mortality of patients with AKI is decreasing. ${ }^{6,71,142}$ In hospital, 90-day and 6-month mortality among patients with AKI treated with RRT have been reported as $35 \%, 45 \%$ and $49 \%$, respectively. ${ }^{63,142}$

The factors that contribute to AKI-associated mortality vary with time and differ in the immediate and long-term. Factors that modify the risk of early mortality occurring in-hospital or less than 90 days after AKI include the primary diagnosis (such as sepsis), severity of acute illness and the burden of acute nonrenal organ dysfunction..$^{70}$ Among early survivors, factors contributing to intermediate and long-term mortality include older age, pre-existing comorbid disease (CKD, cardiovascular disease or malignancy) and incomplete organ recovery with ongoing residual disease. ${ }^{140}$ Although large epidemiological surveys have described the mortality associated with AKI, relatively little insight has been available on the proximate causes of death among patients with AKI. In a cohort study of 3,930 hospitalized patients prospectively identified as having AKI (according to the AKIN criteria), in-hospital mortality was $21.9 \%$ and data on the primary cause of death was available for $93.4 \%$ of the deceased patients. ${ }^{143}$ Death was primarily attributed to sepsis $(41.1 \%)$, cardiovascular events (19.2\%) and malignancies (12.9\%), whereas AKI was listed as the primary cause of death in only $3.1 \%$ of patients.

\section{Recovery of kidney function}

Nonrecovery of kidney function following an episode of AKI is a major morbid event with long-term implications for patients and health resources. No consensus on a definition of renal recovery after AKI exists; however, the majority of studies have defined renal nonrecovery as dialysis dependence. In large observational cohort studies of critically ill patients with severe AKI requiring RRT, the rate of dialysis dependence at hospital discharge was 13-29\%. ${ }^{15,68,144-146}$ Among survivors of AKI, the rate of dialysis dependence seems to decrease at 6 months and 12 months after AKI onset; however, this result is often confounded by deaths that occur predominantly among those patients who remain on dialysis. ${ }^{15,141}$

Several patient-level susceptibilities modify the likelihood of nonrecovery from AKI and rapid progression to ESRD, in particular older age ${ }^{147}$ and severity of CKD at baseline (Figure 3). ${ }^{140,148}$ Both the severity of AKI and the number of AKI episodes are associated with the development of incident CKD and ESRD. ${ }^{149,150}$ Hospitalized patients might be exposed to multiple, potentially avoidable inciting events during their illness that might worsen AKI and reduce the probability of recovery. ${ }^{102,103,105,107,108}$ Although no validated scoring systems that reliably predict recovery of kidney function after AKI are currently available, data from studies that integrated novel biomarkers of kidney damage (that is, NGAL) into models for clinical risk prediction are promising. ${ }^{151}$

Fluid accumulation is associated with misclassification and delayed diagnosis of $\mathrm{AKI}^{23,24}$ and several studies have shown that fluid accumulation and overload independently predict mortality in patients with AKI. ${ }^{129-131,152}$ Moreover, fluid overload at the time of initiation of RRT has been associated with nonrecovery of kidney function. ${ }^{153}$ These data suggest that a metric of fluid overload should be considered an important trigger for initiation of RRT, and might be more relevant for clinical decision support than serum creatinine levels alone. In addition, a systematic review suggested that delayed initiation of RRT in critically ill patients with AKI is associated with a non-significant increase in kidney nonrecovery. ${ }^{153}$ Further high-quality randomized trials to investigate this issue are expected. ${ }^{154,155}$ The impact of the initial RRT modality in critically ill patients with AKI on recovery 
Table 2 | Selected studies evaluating the impact of initial RRT modality on renal recovery after AKI

\begin{tabular}{|c|c|c|c|c|c|c|}
\hline Study & Location & $\begin{array}{l}\text { Year(s) of } \\
\text { enrolment }\end{array}$ & Design & $\begin{array}{l}\text { Population } \\
\text { (n) }\end{array}$ & $\begin{array}{l}\text { Definition of } \\
\text { renal recovery }\end{array}$ & $\begin{array}{l}\text { Outcome } \\
\text { (CRRT versus IRRT) }\end{array}$ \\
\hline $\begin{array}{l}\text { Mehta } \\
\text { et al. }{ }^{159}\end{array}$ & USA & 1991-1995 & $\begin{array}{l}\text { Multicentre, randomized } \\
\text { clinical trial }\end{array}$ & $\begin{array}{l}\text { Mixed ICU } \\
(166)\end{array}$ & $\begin{array}{l}\mathrm{SCr} \leq 177 \mu \mathrm{mol} / \mathrm{I} \\
(2 \mathrm{mg} / \mathrm{dl})\end{array}$ & $\begin{array}{l}\uparrow \text { Complete recovery with } \\
\text { CRRT }\end{array}$ \\
\hline Bell et al. ${ }^{144}$ & Sweden & 1995-2004 & $\begin{array}{l}\text { Multicentre, retrospective } \\
\text { cohort }\end{array}$ & $\begin{array}{l}\text { Mixed ICU } \\
(2,642)\end{array}$ & RRT-free & $\begin{array}{l}\downarrow \text { ESRD with CRRT ( } 8 \% \\
\text { versus } 17 \% \text { ) }\end{array}$ \\
\hline $\begin{array}{l}\text { Uchino } \\
\text { et al. }{ }^{161}\end{array}$ & Worldwide & 2000-2001 & $\begin{array}{l}\text { Multicentre, prospective } \\
\text { cohort }\end{array}$ & $\begin{array}{l}\text { Mixed ICU } \\
(1,218)\end{array}$ & RRT-free & $\begin{array}{l}\downarrow \text { Dialysis dependence with } \\
\text { CRRT ( } 11 \% \text { versus } 35 \%)\end{array}$ \\
\hline $\begin{array}{l}\text { Jacka } \\
\text { et al. }{ }^{157}\end{array}$ & Canada & 2004 & $\begin{array}{l}\text { Multicentre, retrospective } \\
\text { cohort }\end{array}$ & $\begin{array}{l}\text { Mixed ICU } \\
(116)\end{array}$ & RRT-free & $\begin{array}{l}\downarrow \text { Dialysis dependence with } \\
\text { CRRT ( } 17 \% \text { versus } 64 \%)\end{array}$ \\
\hline Lin et al. ${ }^{158}$ & Taiwan & 2002-2006 & $\begin{array}{l}\text { Multicentre, prospective } \\
\text { cohort }\end{array}$ & $\begin{array}{l}\text { Surgical ICU } \\
(342)\end{array}$ & RRT-free & $\uparrow$ Recovery with CRRT \\
\hline $\begin{array}{l}\text { Cartin-Ceba } \\
\text { et al. } .^{156}\end{array}$ & USA & 2003-2006 & $\begin{array}{l}\text { Multicentre, retrospective } \\
\text { cohort }\end{array}$ & $\begin{array}{l}\text { Mixed ICU } \\
(11,664)\end{array}$ & NA & $\uparrow$ ESRD with IRRT \\
\hline $\begin{array}{l}\text { Andrikos } \\
\text { et al. }{ }^{59}\end{array}$ & Greece & 2008 & $\begin{array}{l}\text { Multicentre, prospective } \\
\text { cohort }\end{array}$ & $\begin{array}{l}\text { Mixed ICU } \\
(170)\end{array}$ & RRT-free & $\begin{array}{l}\downarrow \text { Dialysis dependence with } \\
\text { CRRT ( } 15 \% \text { versus } 25 \% \text { ) }\end{array}$ \\
\hline $\begin{array}{l}\text { Wald } \\
\text { et al. }{ }^{162}\end{array}$ & Canada & 1996-2009 & $\begin{array}{l}\text { Multicentre, retrospective } \\
\text { cohort, } \geq 90 \text { day survival } \\
\text { after initiation of RRT }\end{array}$ & $\begin{array}{l}\text { Mixed ICU } \\
(4,008)\end{array}$ & RRT-free & $\begin{array}{l}\downarrow \text { ESRD with CRRT (16\% } \\
\text { versus } 26 \% \text { ) }\end{array}$ \\
\hline
\end{tabular}

Abbreviations: CRRT, continuous RRT; ESRD, end-stage renal disease; ICU, intensive care unit; IRRT, intermittent RRT; NA, not applicable; RRT, renal replacement therapy; SCr, serum creatinine.

of kidney function is an area of renewed interest. ${ }^{141,142}$ Initial renal support with continuous RRT (CRRT), compared with intermittent RRT is associated with a higher likelihood of recovery to dialysis independence (Table 2). ${ }^{141,144,156-162}$

Few data are available on the long-term risk of incident CKD and progression to ESRD in patients with less-severe forms of AKI. The risk of incident ESRD is reported to be 2.7 -fold higher among critically ill patients with AKI who do not require RRT than among patients without AKI. ${ }^{139}$ These patients are also at increased risk of major cardiovascular events, rehospitalization and mortality. ${ }^{139,163}$ However, following an episode of AKI, early as opposed to late recovery to baseline kidney function is associated with a lower risk of adverse events and long-term mortality. ${ }^{114,164}$

\section{Health-related quality of life and disability}

Health-related quality of life (HRQL) and residual disability are increasingly recognized as important patientcentred outcomes following acute illness complicated by AKI. ${ }^{165}$ A number of studies have described HRQL for patients with AKI associated with critical illness (Table 3). ${ }^{71,136,166-171}$ The majority of these studies are fairly small, single-centre and primarily focused on functional disability and HRQL among survivors of severe AKI requiring RRT. In general, HRQL is lower at hospital discharge and at 6 months after AKI onset in survivors of AKI compared with the age and sex-matched general population. Older age, greater comorbid disease, higher illness severity, longer durations of ICU and hospital stays, and dialysis dependence are associated with significantly lower HRQL. ${ }^{169,171}$ At 6 months after initiation of RRT, the physical components of HRQL in patients with AKI were generally more affected than the mental components, ${ }^{167}$ but better cognitive function was reported in the dialysis-independent survivors. ${ }^{169}$ Poor HRQL has been shown to predict mortality in survivors of AKI at 1 year. ${ }^{170}$ However, despite lower perceived HRQL compared with an age and sex-matched general population, many survivors of AKI requiring RRT report that their HRQL is acceptable and they would choose to receive the same treatment course again. ${ }^{167}$

Few studies have evaluated HRQL following AKI not requiring RRT. ${ }^{136,168}$ Despite lower baseline HRQL and greater disability compared with a matched general population, survivors of AKI not requiring RRT showed improvements in HRQL at 6 months to levels commensurate with survivors of critical illness without AKI. ${ }^{168}$

\section{Economics of AKI}

Resource implications of AKI

The development of AKI in hospitalized patients increases direct and indirect health-care costs and resource utilization across a broad range of conditions. ${ }^{52}$ $\mathrm{AKI}$ is associated with greater investigations and monitoring, unplanned or longer ICU stays, prolonged hospitalization and an increased risk of early rehospitalization. In a US study, ${ }^{52}$ hospitalized patients who developed KDIGO stage 2 AKI had a reported 6.5-fold increased adjusted odds ratio for death, a prolonged hospital stay (>3.5 days), and an additional USD \$9,000 in hospital costs compared with hospitalized patients who did not develop AKI. ${ }^{52}$

Uncomplicated AKI, defined as AKI not in association with critical illness, contributes an excess $\$ 2,600$ in attributable costs and a median of five additional days of hospitalization. ${ }^{172}$ These direct hospital costs exceed those of several more-prevalent conditions including hospitalizations for heart failure $(\$ 2,200)$, pneumonia $(\$ 2,100)$ and gastrointestinal bleeding $(\$ 2,100) .{ }^{52}$ 
Table 3 | Studies evaluating HRQL among survivors of AKI

\begin{tabular}{|c|c|c|c|c|c|c|}
\hline Study & Location & $\begin{array}{l}\text { Years of } \\
\text { enrolment }\end{array}$ & Design & $\begin{array}{l}\text { Population } \\
(n)\end{array}$ & Instrument & Outcome \\
\hline $\begin{array}{l}\text { Korkeila } \\
\text { et al. }{ }^{145}\end{array}$ & Finland & 1992-1993 & $\begin{array}{l}\text { Single-centre, } \\
\text { retrospective } \\
\text { cohort }\end{array}$ & $\begin{array}{l}\text { Mixed ICU, } \\
\text { requiring RRT } \\
(3,447)\end{array}$ & $\begin{array}{l}\text { NHP } \\
\text { and ADL }\end{array}$ & $\begin{array}{l}\downarrow \text { HRQL, reduced energy and limited } \\
\text { physical mobility at } 6 \text { months after AKI }\end{array}$ \\
\hline $\begin{array}{l}\text { Ahlstrom } \\
\text { et al. }{ }^{166}\end{array}$ & Finland & 1998-2002 & $\begin{array}{l}\text { Single-centre, } \\
\text { prospective } \\
\text { cohort }\end{array}$ & $\begin{array}{l}\text { Mixed ICU, } \\
\text { requiring RRT } \\
\text { (153) }\end{array}$ & $E Q-5 D$ & $\begin{array}{l}\downarrow \text { HRQL and quality-adjusted survival in } \\
\text { patients on RRT compared with age and } \\
\text { sex-matched general population }\end{array}$ \\
\hline $\begin{array}{l}\text { Johansen } \\
\text { et al. } .^{169}\end{array}$ & USA & 2003-2007 & $\begin{array}{l}\text { Substudy of } \\
\text { randomized } \\
\text { controlled trial }\end{array}$ & $\begin{array}{l}\text { Mixed ICU, } \\
\text { requiring RRT } \\
\text { (415) }\end{array}$ & $\mathrm{HUI}$ & $\begin{array}{l}\text { Poor HRQL } \\
\text { Longer ICU and hospital stays and dialysis } \\
\text { dependence associated with worse HRQOL }\end{array}$ \\
\hline $\begin{array}{l}\text { Joyce } \\
\text { et al. }{ }^{170}\end{array}$ & USA & 2003-2007 & $\begin{array}{l}\text { Substudy of } \\
\text { randomized } \\
\text { controlled trial }\end{array}$ & $\begin{array}{l}\text { Mixed ICU, } \\
\text { requiring RRT } \\
\text { (439) }\end{array}$ & $\mathrm{HUI}$ & $\begin{array}{l}\text { HRQL poor and associated with } \uparrow \text { risk of } \\
\text { 1-year mortality }\end{array}$ \\
\hline $\begin{array}{l}\text { Morsch } \\
\text { et al. }{ }^{171}\end{array}$ & Brazil & 2006-2008 & $\begin{array}{l}\text { Single-centre, } \\
\text { prospective } \\
\text { cohort }\end{array}$ & $\begin{array}{l}\text { Mixed ICU, } \\
\text { requiring RRT } \\
\text { (68) }\end{array}$ & SF-36 & $\begin{array}{l}\uparrow \mathrm{HRQL} \text { at } 6 \text { months associated with } \\
\text { younger age, fewer comorbidities, } \\
\text { less-severe illness, no sepsis and shorter } \\
\text { ICU stay }\end{array}$ \\
\hline $\begin{array}{l}\text { Abelha } \\
\text { et al. }{ }^{136}\end{array}$ & Portugal & 2006-2008 & $\begin{array}{l}\text { Single-centre, } \\
\text { retrospective } \\
\text { cohort }\end{array}$ & $\begin{array}{l}\text { Surgical, AKI } \\
\text { according to } \\
\text { AKIN criteria } \\
\text { (50) }\end{array}$ & $\begin{array}{l}\text { SF-36 } \\
\text { and ADL }\end{array}$ & $\begin{array}{l}\downarrow \mathrm{HRQL} \text { and } \uparrow \mathrm{ADL} \text { at } 6 \text { months in patients } \\
\text { with AKI compared with those without AKI }\end{array}$ \\
\hline $\begin{array}{l}\text { Delannoy } \\
\text { et al. } .^{167}\end{array}$ & France & 2007-2008 & $\begin{array}{l}\text { Multicentre, } \\
\text { prospective } \\
\text { cohort }\end{array}$ & $\begin{array}{l}\text { Mixed ICU, } \\
\text { requiring RRT } \\
\text { (77) }\end{array}$ & $\begin{array}{l}\text { SF-36 } \\
\text { and ADL }\end{array}$ & $\begin{array}{l}\downarrow \text { but acceptable HRQL in survivors of AKI } \\
\text { compared with the general population } \\
\text { Improved HRQOL of AKI survivors } \\
1-6 \text { months after AKI; physical } \\
\text { components more severely affected than } \\
\text { mental components }\end{array}$ \\
\hline $\begin{array}{l}\text { Vaara } \\
\text { et al. }\end{array}$ & Finland & 2007-2008 & $\begin{array}{l}\text { Multicentre, } \\
\text { retrospective } \\
\text { cohort }\end{array}$ & $\begin{array}{l}\text { Mixed ICU, } \\
\text { requiring RRT } \\
(1,686)\end{array}$ & $E Q-5 D$ & $\begin{array}{l}\text { At } 6 \text { months, HRQL was similar for } \\
\text { survivors of AKI on RRT and those who } \\
\text { did not require RRT }\end{array}$ \\
\hline $\begin{array}{l}\text { Hofhuis } \\
\text { et al. }{ }^{168}\end{array}$ & Netherlands & 2000-2007 & $\begin{array}{l}\text { Single-centre, } \\
\text { prospective } \\
\text { cohort }\end{array}$ & $\begin{array}{l}\text { Mixed ICU, AKI } \\
\text { according to } \\
\text { RIFLE criteria } \\
\text { (398) }\end{array}$ & $\begin{array}{l}\text { SF-36 } \\
\text { (by proxy) }\end{array}$ & $\begin{array}{l}\downarrow \text { HRQL at baseline and at 6-month } \\
\text { follow-up in survivors of AKI compared } \\
\text { with the general population } \\
\downarrow \text { HRQL at discharge in AKI survivors but } \\
\text { no difference at } 6 \text { months compared with } \\
\text { patients without AKI }\end{array}$ \\
\hline
\end{tabular}

Abbreviations: ADL, activities of daily living; AKI, acute kidney injury; AKIN, Acute Kidney Injury Network; EQ-5D, EuroQOL; HRQL, health-related quality of life; HUI, health utilities index; ICU, intensive care unit; NHP, Nottingham Health Profile; RIFLE, risk, injury, failure, loss, end-stage renal disease; RRT, renal replacement

therapy; SF-36, short form 36.

The development of AKI in critically ill patients contributes to prolonged mechanical ventilation, failed weaning from mechanical ventilation, greater use of tracheostomy and longer ICU stays. ${ }^{173,174}$ In patients who develop AKI after cardiac surgery, the attributable cost and utilization of RRT increases with the severity of injury. ${ }^{175}$ Patients with KDIGO stage 1 AKI after cardiac surgery had a 1.6-fold longer duration of ICU stay and a 1.6-fold increase in total post-operative costs compared with those who did not develop AKI. ${ }^{175}$ Moreover, hospitalized patients with AKI who did not require RRT had higher rates of rehospitalization (adjusted hazard ratio $1.21,95 \% \mathrm{CI}, 1.18-1.24$ ) compared to those without AKI. ${ }^{139}$

\section{Resource implications of acute RRT}

The initiation of RRT in patients with severe AKI represents a measurable increase in the complexity of care and associated costs. The application of RRT across different centres is variable and is associated with differences in adjusted mortality. ${ }^{176}$ However, adjusted mortality might be lower in larger centres that perform a higher annual volume of treatments than in smaller centres. ${ }^{177}$

\section{Haemodialysis}

The daily cost of CRRT is more than that of intermittent haemodialysis. ${ }^{178-182}$ In an analysis of data from 53 centres in 23 countries, the median cost of CRRT per treatment day was $\$ 290$ more expensive than that of intermittent haemodialysis; however, the median cost differences were highly variable across centres (the median daily cost of CRRT compared with intermittent haemodialysis ranged from $\$ 3,630$ excess to $\$ 379$ less). ${ }^{181}$ The greatest costs attributable to CRRT are for replacement and dialysate fluids and the extracorporeal circuit. In a Canadian retrospective cohort study that evaluated the immediate and long-term costs of RRT modalities, the weekly cost of daily CRRT ranged from $\$ 3,283$ to $\$ 4,819$ (depending on the specific therapy and anticoagulant used) compared with only $\$ 1,263$ for three times weekly intermittent haemodialysis. ${ }^{179}$ The direct costs of any RRT are predominantly attributable to 
human resources (such as dialysis nurses), extracorporeal circuits and filters, replacement and dialysate fluids and anticoagulants.

The costs associated with replacement and dialysis fluids for CRRT might be modestly reduced by ensuring a dose-delivery of $25 \mathrm{ml} / \mathrm{kg} / \mathrm{h}$ or timely transition to intermittent haemodialysis when physiologically appropriate for the patient. ${ }^{181}$ In-hospital and 1-year direct health-care costs are lower among AKI survivors with renal recovery ( $\$ 44,921$ and $\$ 10,541$, respectively) than among those who remain on dialysis $(\$ 52,778$ and $\$ 69,011$, respectively). ${ }^{179}$ Higher rates of renal recovery and dialysis independence have been reported among survivors of AKI whose initial therapy was CRRT compared with those who initially received intermittent haemodialysis, suggesting that the continuous therapy might prove to be cost-effective in the long-term. ${ }^{144,160-162}$ The role of hybrid RRTs, such as slow low-efficiency dialysis, is still being defined. ${ }^{183}$

\section{Peritoneal dialysis}

In many regions of the world, peritoneal dialysis is a more commonly used renal replacement modality in patients with severe AKI than is CRRT or intermittent haemodialysis. ${ }^{184,185} \mathrm{~A}$ randomized trial that included 70 critically ill adults with septic AKI, reported that CRRT compared with peritoneal dialysis was associated with faster resolution of azotemic and metabolic complications, higher survival, and lower relative costs per life saved (that is, greater cost effectiveness). ${ }^{185}$ However, a number of potential methodological concerns regarding this trial have cast doubt on these findings. ${ }^{186,187}$ A systematic review of 24 studies, which included 1,556 patients with AKI, compared outcomes of peritoneal dialysis with those of other forms of extracorporeal blood purification and found no statistically significant difference in mortality despite the overall low methodological quality of the included studies. ${ }^{184}$ Subsequent studies have suggested that high volume continuous peritoneal dialysis using an automated cycler in patients with AKI can achieve reasonable azotemic, metabolic and fluid balance control with a low rate of complications. ${ }^{188-190}$ Indeed, peritoneal dialysis is an important RRT modality in developing regions where it might not only be costeffective relative to CRRT, but might be the only option available. ${ }^{191}$ Additional high quality studies are needed to increase our understanding of the role of peritoneal dialysis in AKI.

\section{Long-term cost-effectiveness of RRT}

Few studies have evaluated the cost-effectiveness of RRT in critically ill patients with AKI beyond the immediate direct costs. ${ }^{145}$ In the SUPPORT study, the estimated cost per quality-adjusted life-year (QALY) saved for critically ill patients with AKI started on RRT (compared with withholding support and allowing death to occur) was $\$ 128,200 .{ }^{165}$ In this study, which had a follow-up duration of 4.4 years, median patient survival was 32 days and only $27 \%$ of patients were alive at 5 months. Even among those patients deemed most likely to survive, the cost per
QALY saved was high at $\$ 61,900$. In a Finnish cohort of 410 critically ill patients with AKI treated with RRT, the overall cost per QALY saved during 5-year follow up was poor $(>\$ 339,729)$ and was excessive in older patients $(>\$ 1,358,904) .{ }^{192}$ However, from a societal perspective, the costs were more acceptable in those patients who survived for $>1$ year $(<\$ 67,945$ per QALY saved). In both of these studies the outcomes among survivors of AKI were reasonably good as defined by the patients; however, the cost of RRT far exceeded the commonly cited $\$ 50,000$ per QALY saved threshold for cost-effective care.

\section{Incident CKD and progression to ESRD}

$\mathrm{AKI}$ is an independent risk for incident CKD and progression to ESRD, ${ }^{139,149,163,193}$ with predictable implications for health-care costs at the patient and societal level. The attributable annual costs of CKD to the Medicare programme have been estimated as minimal for stage 1 CKD, $\$ 1,700$ for stage $2 \mathrm{CKD}, \$ 2,500$ for stage $3 \mathrm{CKD}$ and $\$ 12,700$ for stage $4 \mathrm{CKD},{ }^{194}$ whereas the annual attributable costs of ESRD, although variable by RRT modality, average approximately $\$ 52,236 .{ }^{195} \mathrm{ESRD}$ is responsible for approximately $1.2 \%$ of total health care expenditure in Canada ${ }^{195}$ and $1-2 \%$ of the total National Health Service budget in the UK. ${ }^{196}$ In the USA, costs are more difficult to estimate but data from the US Renal Data System suggest that ESRD accounts for approximately $6.7 \%$ of all Medicare expenditure. ${ }^{197}$ Incident CKD and progression to ESRD among children and adults carries a considerable individual and societal burden. CKD is associated with higher risk of hospitalizations, cardiovascular events and mortality ${ }^{90}$ along with reduced HRQL and impaired physical function. ${ }^{198,199}$

The long-term economic implications for children surviving an episode of AKI are particularly relevant. ${ }^{86,200}$ In a small cohort study of critically ill children with AKI $(n=226)$ in New Zealand, the majority of patients survived but $40 \%$ had persistent abnormalities (for example, hypertension, abnormal urinalysis) at hospital discharge, suggesting ongoing kidney injury. ${ }^{86}$ In a Canadian 3-year follow-up study of critically ill children with AKI $(n=126), 10 \%$ of survivors had evidence of CKD with a higher incidence in those with more-severe AKI. ${ }^{200} \mathrm{~A}$ relative paucity of longer-term epidemiological evaluations of kidney health among children surviving an episode of AKI exists. Among children and adolescents, the long-term sequelae and the economic impact of AKI progression to CKD are potentially devastating and might include reduced HRQL, depression, social isolation and education and employment constraints. ${ }^{201,202}$ Further studies are needed to quantify the full economic and social implications of CKD and ESRD among children and adults following an episode of AKI, including the number of productive years lost and the effects on life expectancy, ability to enter the workforce and use of social assistance.

\section{Conclusions}

AKI is a problem of epidemic proportions and likely deserves similar attention as other common medical 
problems encountered in acute care medicine, such as acute myocardial infarction and stroke, which are associated with similar risks of adverse outcomes. Abundant data confirm that the incidence of AKI, particularly in hospitalized patients, is rising. This increasing incidence is largely attributable to a higher prevalence of susceptibilities and heightened exposure to potentially modifiable risks during hospitalization. AKI is associated with an increased risk of adverse outcomes, including shortterm and long-term mortality, incident $\mathrm{CKD}$, accelerated progression to ESRD and reduced HRQL, and also contributes to excess consumption of healthcare resources. The downstream economic impact of AKI might be profound, particularly among survivors who fail to recover kidney function and remain dialysis dependent.

Future research will be directed at improving these poor outcomes associated with AKI by focusing on: improved calibration in the diagnostic criteria for AKI to enable early and reliable identification of those patients who are most at-risk of AKI (for example, understanding the role of novel kidney damage biomarkers and fluid balance); evaluation of the impact of adherence to current KDIGO clinical practice guidelines for better identification and management of patients with AKI; evaluation of novel therapeutics aimed at reducing the incidence of AKI and/or mitigating the development of maladaptive repair during recovery from AKI to reduce the incidence of incident or worsening CKD; and better understanding the optimal application of acute RRT in those developing worsening or severe AKI (that is, when to ideally start and discontinue and the ideal RRT modality to use for selected circumstances).

\begin{tabular}{l} 
Review criteria \\
\hline A search for original articles published between 1980 and \\
2013 and focusing on acute kidney injury was performed \\
in MEDLINE and PubMed. The search terms used were \\
"acute kidney injury OR acute renal failure", "renal \\
replacement therapy OR continuous OR intermittent OR \\
peritoneal", "epidemiology OR incidence", "mortality", \\
"renal recovery AND chronic kidney disease OR end \\
stage renal disease", “quality of life”, "economic OR cost \\
effectiveness OR quality-adjusted life year", alone and in \\
combination. All articles identified were English-language, \\
full-text papers. We also searched the reference lists of \\
identified articles for further relevant papers.
\end{tabular}

1. Bellomo, R. The epidemiology of acute renal failure: 1975 versus 2005. Curr. Opin. Crit. Care 12, 557-560 (2006).

2. Susantitaphong, P. et al. World incidence of AKI: a meta-analysis. Clin. J. Am. Soc. Nephrol. 8, 1482-1493 (2013).

3. Uchino, S. The epidemiology of acute renal failure in the world. Curr. Opin. Crit. Care 12, 538-543 (2006).

4. Lameire, N. H. et al. Acute kidney injury: an increasing global concern. Lancet 382, 170-179 (2013).

5. Xue, J. L. et al. Incidence and mortality of acute renal failure in Medicare beneficiaries, 1992 to 2001. J. Am. Soc. Nephrol. 17, 1135-1142 (2006).

6. Waikar, S. S., Curhan, G. C., Wald, R., McCarthy, E. P. \& Chertow, G. M. Declining mortality in patients with acute renal failure, 1988 to 2002. J. Am. Soc. Nephrol. 17, 1143-1150 (2006).

7. Kellum, J. A., Bellomo, R. \& Ronco, C. Kidney attack. JAMA 307, 2265-2266 (2012).

8. Li, P. K. et al. Acute kidney injury: global health alert. Kidney Int. 83, 372-376 (2013).

9. Hoste, E. A. et al. The epidemiology of cardiac surgery-associated acute kidney injury. Int. J. Artif. Organs 31, 158-165 (2008).

10. Bellomo, R. et al. Acute renal failure-definition, outcome measures, animal models, fluid therapy and information technology needs: the second international consensus conference of the Acute Dialysis Quality Initiative (ADQI) Group. Crit. Care 8, R204-R212 (2004).

11. Mehta, R. L. et al. Acute Kidney Injury Network: report of an initiative to improve outcomes in acute kidney injury. Crit. Care 11, R31 (2007).

12. Kellum, J. A., Levin, N., Bouman, C. \& Lameire, N. Developing a consensus classification system for acute renal failure. Curr. Opin. Crit. Care 8, 509-514 (2002).

13. Kidney Disease Improving Global Outcomes. KDIGO clinical practice guidelines on acute kidney injury. Kidney Int. Suppl. 2, 8-12 (2012).

14. Ricci, Z., Cruz, D. \& Ronco, C. The RIFLE criteria and mortality in acute kidney injury: a systematic review. Kidney Int. 73, 538-546 (2008).

15. Bagshaw, S. M. et al. Prognosis for long-term survival and renal recovery in critically ill patients with severe acute renal failure: a population-based study. Crit. Care $\mathbf{9}$, R700-R709 (2005).

16. de Mendonca, A. et al. Acute renal failure in the ICU: risk factors and outcome evaluated by the SOFA score. Intensive Care Med. 26, 915-921 (2000).

17. Bagshaw, S. M. et al. A comparison of observed versus estimated baseline creatinine for determination of RIFLE class in patients with acute kidney injury. Nephrol. Dial. Transplant. 24, 2739-2744 (2009).

18. Zavada, J. et al. A comparison of three methods to estimate baseline creatinine for RIFLE classification. Nephrol. Dial. Transplant. 25, 3911-3918 (2010).

19. Siew, E. D. et al. Use of multiple imputation method to improve estimation of missing baseline serum creatinine in acute kidney injury research. Clin. J. Am. Soc. Nephrol. 8, 10-18 (2013).

20. Pickering, J. W. \& Endre, Z. H. Back-calculating baseline creatinine with MDRD misclassifies acute kidney injury in the intensive care unit. Clin. J. Am. Soc. Nephrol. 5, 1165-1173 (2010).

21. Pickering, J. W. \& Endre, Z. H. GFR shot by RIFLE: errors in staging acute kidney injury. Lancet $\mathbf{3 7 3}$, 1318-1319 (2009).

22. Doi, K. et al. Reduced production of creatinine limits its use as marker of kidney injury in sepsis. J. Am. Soc. Nephrol. 20, 1217-1221 (2009).

23. Liu, K. D. et al. Acute kidney injury in patients with acute lung injury: impact of fluid accumulation on classification of acute kidney injury and associated outcomes. Crit. Care Med. 39, 2665-2671 (2011).

24. Macedo, E. et al. Fluid accumulation, recognition and staging of acute kidney injury in critically-ill patients. Crit. Care 14, R82 (2010).

25. Pickering, J. W., Ralib, A. M. \& Endre, Z. H. Combining creatinine and volume kinetics identifies missed cases of acute kidney injury following cardiac arrest. Crit. Care 17, R7 (2013)

26. Macedo, E., Malhotra, R., Bouchard, J., Wynn, S. K. \& Mehta, R. L. Oliguria is an early predictor of higher mortality in critically ill patients. Kidney Int. 80, 760-767 (2011).

27. Mandelbaum, T. et al. Empirical relationships among oliguria, creatinine, mortality, and renal replacement therapy in the critically ill. Intensive Care Med. 39, 414-419 (2013).

28. Prowle, J. R. et al. Oliguria as predictive biomarker of acute kidney injury in critically ill patients. Crit. Care 15, R172 (2011).

29. Macedo, E., Malhotra, R., Claure-Del Granado, R. Fedullo, P. \& Mehta, R. L. Defining urine output criterion for acute kidney injury in critically ill patients. Nephrol. Dial. Transplant. 26, 509-515 (2011).

30. Ralib, A. M., Pickering, J. W., Shaw, G. M. \& Endre, Z. H. The urine output definition of acute kidney injury is too liberal. Crit. Care 17, R112 (2013)

31. McCullough, P. A. et al. Implementation of novel biomarkers in the diagnosis, prognosis, and management of acute kidney injury: executive summary from the tenth consensus conference of the Acute Dialysis Quality Initiative (ADQI). Contrib. Nephrol. 182, 5-12 (2013).

32. Bagshaw, S. M., Zappitelli, M. \& Chawla, L. S. Novel biomarkers of AKI: the challenges of progress 'amid the noise and the haste'. Nephrol. Dial. Transplant. 28, 235-238 (2013).

33. Parikh, C. R. et al. Postoperative biomarkers predict acute kidney injury and poor outcomes after pediatric cardiac surgery. J. Am. Soc. Nephrol. 22, 1737-1747 (2011).

34. Siew, E. D. et al. Distinct injury markers for the early detection and prognosis of incident acute kidney injury in critically ill adults with preserved kidney function. Kidney Int. 84, 786-794 (2013).

35. Nickolas, T. L. et al. Diagnostic and prognostic stratification in the emergency department using urinary biomarkers of nephron damage: a multicenter prospective cohort study. J. Am. Coll. Cardiol. 59, 246-255 (2012). 
36. Nickolas, T. L. et al. Sensitivity and specificity of a single emergency department measurement of urinary neutrophil gelatinase-associated lipocalin for diagnosing acute kidney injury. Ann. Intern. Med. 148, 810-819 (2008).

37. Kashani, K. et al. Discovery and validation of cell cycle arrest biomarkers in human acute kidney injury. Crit. Care 17, R25 (2013)

38. Bagshaw, S. M. Subclinical acute kidney injury: a novel biomarker-defined syndrome. Crit. Care Resusc. 13, 201-203 (2011).

39. Haase, M., Kellum, J. A. \& Ronco, C. Subclinical $\mathrm{AKI}$-an emerging syndrome with important consequences. Nat. Rev. Nephrol. 8, 735-739 (2012).

40. Haase, M. et al. The outcome of neutrophil gelatinase-associated lipocalin-positive subclinical acute kidney injury: a multicenter pooled analysis of prospective studies. J. Am. Coll. Cardiol. 57, 1752-1761 (2011).

41. Colpaert, K. et al. Impact of real-time electronic alerting of acute kidney injury on therapeutic intervention and progression of RIFLE class. Crit. Care Med. 40, 1164-1170 (2012).

42. Brown, J. R., Kramer, R. S., Coca, S. G. \& Parikh, C. R. The prognostic value of using the duration of acute kidney injury in cardiac surgery: an example using two antifibrinolytics. J. Extra Corpor. Technol. 43, 227-231 (2011).

43. Goldstein, S. L. et al. Electronic health record identification of nephrotoxin exposure and associated acute kidney injury. Pediatrics 132 e756-e767 (2013).

44. Selby, N. M. et al. Use of electronic results reporting to diagnose and monitor $\mathrm{AKI}$ in hospitalized patients. Clin. J. Am. Soc. Nephrol. 7, 533-540 (2012).

45. Hsu, C. Y. et al. Community-based incidence of acute renal failure. Kidney Int. 72, 208-212 (2007).

46. Liangos, O. et al. Epidemiology and outcomes of acute renal failure in hospitalized patients: a national survey. Clin. J. Am. Soc. Nephrol. 1, 43-51 (2006).

47. Swaminathan, M. et al. Trends in acute renal failure associated with coronary artery bypass graft surgery in the United States. Crit. Care Med. 35, 2286-2291 (2007).

48. Fujii, T., Uchino, S., Takinami, M. \& Bellomo, R. Subacute kidney injury in hospitalized patients. Clin. J. Am. Soc. Nephrol. http://dx.doi.org/ 10.2215/CJN.04120413.

49. Waikar, S. S. et al. Validity of international classification of diseases, ninth revision, clinical modification codes for acute renal failure. J. Am. Soc. Nephrol. 17, 1688-1694 (2006).

50. Hwang, Y. J. et al. Validity of the international classification of diseases, tenth revision code for acute kidney injury in elderly patients at presentation to the emergency department and at hospital admission. BMJ Open 2, e001821 (2012).

51. Ali, T. et al. Incidence and outcomes in acute kidney injury: a comprehensive population-based study. J. Am. Soc. Nephrol. 18, 1292-1298 (2007).

52. Chertow, G. M., Burdick, E., Honour, M., Bonventre, J. V. \& Bates, D. W. Acute kidney injury, mortality, length of stay, and costs in hospitalized patients. J. Am. Soc. Nephrol. 16, 3365-3370 (2005).

53. Lassnigg, A. et al. Minimal changes of serum creatinine predict prognosis in patients after cardiothoracic surgery: a prospective cohort study. J. Am. Soc. Nephrol. 15, 1597-1605 (2004).

54. Hou, S. H., Bushinsky, D. A., Wish, J. B., Cohen, J. J. \& Harrington, J. T. Hospital-acquired renal insufficiency: a prospective study. Am. J. Med. 74, 243-248 (1983).

55. Nash, K., Hafeez, A. \& Hou, S. Hospital-acquired renal insufficiency. Am. J. Kidney Dis. 39, 930-936 (2002).

56. Uchino, S., Bellomo, R., Goldsmith, D., Bates, S. \& Ronco, C. An assessment of the RIFLE criteria for acute renal failure in hospitalized patients. Crit. Care Med. 34, 1913-1917 (2006).

57. Hsu, R. K., McCulloch, C. E., Dudley, R. A., Lo, L. J. \& Hsu, C. Y. Temporal changes in incidence of dialysis-requiring AKI. J. Am. Soc. Nephrol. 24, 37-42 (2013).

58. Siddiqui, N. F. et al. Secular trends in acute dialysis after elective major surgery-1995 to 2009. CMAJ 184, 1237-1245 (2012).

59. Andrikos, E. et al. Epidemiology of acute renal failure in ICUs: a multi-center prospective study. Blood Purif. 28, 239-244 (2009).

60. Bagshaw, S. M. et al. Changes in the incidence and outcome for early acute kidney injury in a cohort of Australian intensive care units. Crit. Care 11, R68 (2007).

61. Bagshaw, S. M., George, C., Dinu, I. \& Bellomo, R. A multi-centre evaluation of the RIFLE criteria for early acute kidney injury in critically ill patients. Nephrol. Dial. Transplant. 23 1203-1210 (2008).

62. Medve, L. et al. Epidemiology of acute kidney injury in Hungarian intensive care units: a multicenter, prospective, observational study. BMC Nephrol. 12, 43 (2011).

63. Nisula, S. et al. Incidence, risk factors and 90day mortality of patients with acute kidney injury in Finnish intensive care units: the FINNAKI study. Intensive Care Med. 39, 420-428 (2013).

64. Piccinni, P. et al. Prospective multicenter study on epidemiology of acute kidney injury in the ICU: a critical care nephrology Italian collaborative effort (NEFROINT). Minerva Anestesiol. 77, 1072-1083 (2011).

65. Poukkanen, M. et al. Acute kidney injury in patients with severe sepsis in Finnish intensive care units. Acta Anaesthesiol. Scand. 57, 863-872 (2013).

66. Thakar, C. V., Christianson, A., Freyberg, R., Almenoff, P. \& Render, M. L. Incidence and outcomes of acute kidney injury in intensive care units: a Veterans Administration study. Crit. Care Med. 37, 2552-2558 (2009).

67. Ostermann, M. \& Chang, R. W. Acute kidney injury in the intensive care unit according to RIFLE. Crit. Care Med. 35, 1837-1843 (2007).

68. Uchino, S. et al. Acute renal failure in critically ill patients: a multinational, multicenter study. JAMA 294, 813-818 (2005).

69. Hoste, E. A. et al. RIFLE criteria for acute kidney injury are associated with hospital mortality in critically ill patients: a cohort analysis. Crit. Care 10, R73 (2006)

70. Clec'h, C. et al. Multiple-center evaluation of mortality associated with acute kidney injury in critically ill patients: a competing risks analysis. Crit. Care 15, R128 (2011).

71. Vaara, S. et al. Population-based incidence, mortality and quality of life in critically ill patients treated with renal replacement therapya nationwide retrospective cohort study in Finnish ICUs. Crit. Care 16, R13 (2012).

72. Riley, S. et al. Renal impairment among acute hospital admissions in a rural Ethiopian hospital. Nephrology (Carlton) 18, 92-96 (2013).

73. Xuan, B. H. et al. Swarming hornet attacks: shock and acute kidney injury-a large case series from Vietnam. Nephrol. Dial. Transplant. 25, 1146-1150 (2010).

74. Khakurel, S., Satyal, P. R., Agrawal, R. K., Chhetri, P. K. \& Hada, R. Acute renal failure in a tertiary care center in Nepal. J. Nepal Med. Assoc. 44, 32-35 (2005).

75. Soliman, A. R. Spectrum of acute kidney injury in a tertiary care hospital in Cairo. Arab J. Nephrol. Transplant. 4, 83-86 (2011).

76. Daher, E. F. et al. Leptospirosis-associated acute kidney injury: penicillin at the late stage is still controversial. J. Clin. Pharm. Ther. 37, 420-425 (2012).

77. Liborio, A. B. et al. Acute kidney injury in children with visceral leishmaniasis. Pediatr. Infect. Dis. J. 31, 451-454 (2012).

78. Krishnamurthy, S. et al. Incidence and etiology of acute kidney injury in southern India. Indian J. Pediatr. 80, 183-189 (2013).

79. Shukla, V. S., Singh, R. G., Rathore, S. S. \& Usha. Outcome of malaria-associated acute kidney injury: a prospective study from a single center. Ren. Fail. 35, 801-805 (2013).

80. Lombardi, R., Yu, L., Younes-lbrahim, M. Schor, N. \& Burdmann, E. A. Epidemiology of acute kidney injury in Latin America. Semin. Nephrol. 28, 320-329 (2008).

81. Phillips, L. A. et al. Acute kidney injury risk factor recognition in three teaching hospitals in Ethiopia. S. Afr. Med. J. 103, 413-418 (2013).

82. Coca, S. G., Cho, K. C. \& Hsu, C. Y. Acute kidney injury in the elderly: predisposition to chronic kidney disease and vice versa. Nephron Clin. Pract. 119 (Suppl. 1), c19-c24 (2011).

83. Ishani, A. et al. Acute kidney injury increases risk of ESRD among elderly. J. Am. Soc. Nephrol. 20, 223-228 (2009).

84. Boumendil, A. et al. Treatment intensity and outcome of patients aged 80 and older in intensive care units: a multicenter matchedcohort study. J. Am. Geriatr. Soc. 53, 88-93 (2005).

85. Bagshaw, S. M. et al. Association between renal replacement therapy in critically ill patients with severe acute kidney injury and mortality. J. Crit. Care 28, 1011-1018 (2013).

86. Ball, E. F. \& Kara, T. Epidemiology and outcome of acute kidney injury in New Zealand children. J. Paediatr. Child Health 44, 642-646 (2008).

87. James, M. T. et al. Glomerular filtration rate, proteinuria, and the incidence and consequences of acute kidney injury: a cohort study. Lancet 376, 2096-2103 (2010).

88. Grams, M. E. et al. Albuminuria and estimated glomerular filtration rate independently associate with acute kidney injury. J. Am. Soc. Nephrol. 21, 1757-1764 (2010).

89. Coca, S. G. et al. Preoperative proteinuria predicts acute kidney injury in patients undergoing cardiac surgery. J. Thorac. Cardiovasc. Surg. 143, 495-502 (2012).

90. Go, A. S., Chertow, G. M., Fan, D., McCulloch, C. E. \& Hsu, C. Y. Chronic kidney disease and the risks of death, cardiovascular events, and hospitalization. N. Engl. J. Med. 351, 1296-1305 (2004).

91. Cho, K. \& Hsu, C. Y. Quantifying severity of chronic kidney disease as a risk factor for acute kidney injury. J. Am. Soc. Nephrol. 21, 1602-1604 (2010).

92. Lafrance, J. P., Djurdjev, O. \& Levin, A. Incidence and outcomes of acute kidney injury in a referred chronic kidney disease cohort. Nephrol. Dial. Transplant. 25, 2203-2209 (2010).

93. Kheterpal, S. et al. Development and validation of an acute kidney injury risk index for patients undergoing general surgery: results from a national data set. Anesthesiology 110, 505-515 (2009).

94. Huen, S. C. \& Parikh, C. R. Predicting acute kidney injury after cardiac surgery: a systematic review. Ann. Thorac. Surg. 93, 337-347 (2012). 
95. Mehta, R. H. et al. Bedside tool for predicting the risk of postoperative dialysis in patients undergoing cardiac surgery. Circulation 114, 2208-2216 (2006).

96. Thakar, C. V., Arrigain, S., Worley, S., Yared, J. P. \& Paganini, E. P. A clinical score to predict acute renal failure after cardiac surgery. J. Am. Soc. Nephrol. 16, 162-168 (2005).

97. Benko, A. et al. Canadian association of radiologists: consensus guidelines for the prevention of contrast-induced nephropathy. Can. Assoc. Radiol. J. 58, 79-87 (2007).

98. Schneider, V., Levesque, L. E., Zhang, B. Hutchinson, T. \& Brophy, J. M. Association of selective and conventional nonsteroidal antiinflammatory drugs with acute renal failure: a population-based, nested case-control analysis. Am. J. Epidemiol. 164, 881-889 (2006).

99. Bird, S. T., Etminan, M., Brophy, J. M., Hartzema, A. G. \& Delaney, J. A. Risk of acute kidney injury associated with the use of fluoroquinolones. CMAJ 185, E475-E482 (2013)

100. Dormuth, C. R. et al. Use of high potency statins and rates of admission for acute kidney injury: multicenter, retrospective observational analysis of administrative databases. BMJ 346, f880 (2013)

101. Leonard, C. E. et al. Proton pump inhibitors and traditional nonsteroidal anti-inflammatory drugs and the risk of acute interstitial nephritis and acute kidney injury. Pharmacoepidemiol. Drug Saf. 21, 1155-1172 (2012).

102. Sorli, L. et al. Trough colistin plasma level is an independent risk factor for nephrotoxicity: a prospective observational cohort study. BMC Infect. Dis. 13, 380 (2013).

103. Wikman, P. et al. The significance of antiretroviral-associated acute kidney injury in a cohort of ambulatory human immunodeficiency virus-infected patients. Nephrol. Dial. Transplant. 28, 2073-2081 (2013).

104. Zhao, Y. Y. et al. New fibrate use and acute renal outcomes in elderly adults: a population-based study. Ann. Intern. Med. 156, 560-569 (2012)

105. Cox, Z. L. et al. Adverse drug events during AKI and its recovery. Clin. J. Am. Soc. Nephrol. 8, 1070-1078 (2013).

106. Zappitelli, M., Moffett, B. S., Hyder, A. \& Goldstein, S. L. Acute kidney injury in noncritically ill children treated with aminoglycoside antibiotics in a tertiary healthcare centre. Nephrol. Dial. Transplant. 26, 144-150 (2011).

107. Herrera-Gutierrez, M. E., Seller-Perez, G., Sanchez-Izquierdo-Riera, J. A. \& MaynarMoliner, J. Prevalence of acute kidney injury in intensive care units: the "COrte de prevalencia de disFuncion RenAl y DEpuracion en criticos" point-prevalence multicenter study. J. Crit. Care 28, 687-694 (2013)

108. Ramirez, E. et al. Vancomycin-induced acute kidney injury detected by a prospective pharmacovigilance program from laboratory signals. Ther. Drug Monit. 35, 360-366 (2013).

109. Wunderink, R. G. et al. Linezolid in methicillinresistant Staphylococcus aureus nosocomial pneumonia: a randomized, controlled study. Clin Infect. Dis. 54, 621-629 (2012).

110. Hoste, E. A. et al. Epidemiology of contrastassociated acute kidney injury in ICU patients: a retrospective cohort analysis. Intensive Care Med. 37, 1921-1931 (2011)

111. Kheterpal, S. et al. Predictors of postoperative acute renal failure after noncardiac surgery in patients with previously normal renal function. Anesthesiology 107, 892-902 (2007).

112. Ho, J. et al. Serum creatinine measurement immediately after cardiac surgery and prediction of acute kidney injury. Am. J. Kidney Dis. 59 196-201 (2012).

113. Bastin, A. J. et al. Acute kidney injury after cardiac surgery according to risk/injury/failure/ loss/end-stage, acute kidney injury network, and kidney disease: improving global outcomes classifications. J. Crit. Care 28, 389-396 (2013).

114. Swaminathan, M. et al. Impact of early renal recovery on survival after cardiac surgeryassociated acute kidney injury. Ann. Thorac. Surg. 89, 1098-1104 (2010).

115. Kuitunen, A., Vento, A., Suojaranta-Ylinen, R. \& Pettila, V. Acute renal failure after cardiac surgery: evaluation of the RIFLE classification. Ann. Thorac. Surg. 81, 542-546 (2006).

116. Chertow, G. M., Levy, E. M., Hammermeister, K. E., Grover, F. \& Daley, J. Independent association between acute renal failure and mortality following cardiac surgery. Am. J. Med. 104, 343-348 (1998).

117. Bagshaw, S. M. et al. Early acute kidney injury and sepsis: a multicentre evaluation. Crit. Care 12, R47 (2008).

118. Murugan, R. et al. Acute kidney injury in nonsevere pneumonia is associated with an increased immune response and lower survival. Kidney Int. 77, 527-535 (2010).

119. Bagshaw, S. M. et al. Acute kidney injury in septic shock: clinical outcomes and impact of duration of hypotension prior to initiation of antimicrobial therapy. Intensive Care Med. 35 871-881 (2009).

120. Mehta, R. L. et al. Sepsis as a cause and consequence of acute kidney injury: program to improve care in acute renal disease. Intensive Care Med. 37, 241-248 (2011).

121. Brunkhorst, F. M. et al. Intensive insulin therapy and pentastarch resuscitation in severe sepsis. N. Engl. J. Med. 358, 125-139 (2008).

122. Myburgh, J. A. et al. Hydroxyethyl starch or saline for fluid resuscitation in intensive care. N. Engl. J. Med. 367, 1901-1911 (2012)

123. Perner, A. et al. Hydroxyethyl starch $130 / 0.42$ versus Ringer's acetate in severe sepsis. N. Engl. J. Med. 367, 124-134 (2012).

124. Shaw, A. D. et al. Major complications, mortality, and resource utilization after open abdominal surgery: 0.9\% saline compared to Plasma-Lyte. Ann. Surgery 255, 821-829 (2012).

125. Yunos, N. M. et al. Association between a chloride-liberal vs chloride-restrictive intravenous fluid administration strategy and kidney injury in critically ill adults. JAMA 308, 1566-1572 (2012).

126. Yunos, N. M. et al. The biochemical effects of restricting chloride-rich fluids in intensive care. Crit. Care Med. 39, 2419-2424 (2011).

127. Chowdhury, A. H., Cox, E. F., Francis, S. T. \& Lobo, D. N. A randomized, controlled, doubleblind crossover study on the effects of $2-\mathrm{L}$ infusions of $0.9 \%$ saline and Plasma-Lyte ${ }^{\circledR} 148$ on renal blood flow velocity and renal cortical tissue perfusion in healthy volunteers. Ann. Surg. 256, 18-24 (2012).

128. Grams, M. E. et al. Fluid balance, diuretic use, and mortality in acute kidney injury. Clin. J. Am. Soc. Nephrol. 6, 966-973 (2011).

129. Payen, D. et al. A positive fluid balance is associated with a worse outcome in patients with acute renal failure. Crit. Care 12, R74 (2008).

130. Bouchard, J. et al. Fluid accumulation, survival and recovery of kidney function in critically ill patients with acute kidney injury. Kidney Int. 76 422-427 (2009).

131. Vaara, S. T. et al. Fluid overload is associated with an increased risk for 90-day mortality in critically ill patients with renal replacement therapy: data from the prospective FINNAKI study. Crit. Care 16, R197 (2012).

132. Goldberg, A. \& Hammerman, H. In hospital and 1-year mortality of patients who develop worsening renal function following acute ST-elevation myocardial infarction. Am. Heart $\lrcorner$. 150, 330-337 (2005).

133. Anzai, A. et al. Prognostic significance of acute kidney injury after reperfused ST-elevation myocardial infarction: synergistic acceleration of renal dysfunction and left ventricular remodeling. J. Card. Fail. 16, 381-389 (2010)

134. Marenzi, G. et al. Acute kidney injury in ST-segment elevation acute myocardial infarction complicated by cardiogenic shock at admission. Crit. Care Med. 38, 438-444 (2010).

135. Fonarow, G. C. et al. Risk stratification for in hospital mortality in acutely decompensated heart failure: classification and regression tree analysis. JAMA 293, 572-580 (2005).

136. Abelha, F. J., Botelho, M., Fernandes, V. \& Barros, H. Outcome and quality of life of patients with acute kidney injury after major surgery. Nefrologia 29, 404-414 (2009).

137. Bagshaw, S. M., George, C., Gibney, R. T. \& Bellomo, R. A multi-center evaluation of early acute kidney injury in critically ill trauma patients. Ren. Fail. 30, 581-589 (2008)

138. Lafrance, J. P. \& Miller, D. R. Acute kidney injury associates with increased long-term mortality. J. Am. Soc. Nephrol. 21, 345-352 (2010).

139. Wald, R. et al. Risk of chronic dialysis and death following acute kidney injury. Am. J. Med. 125 , 585-593 (2012)

140. Wu, V. C. et al. Acute-on-chronic kidney injury at hospital discharge is associated with long-term dialysis and mortality. Kidney Int. $\mathbf{8 0}$ 1222-1230 (2011).

141. Palevsky, P. M. et al. Intensity of renal support in critically ill patients with acute kidney injury. N. Engl. J. Med. 359, 7-20 (2008)

142. The RENAL Replacement Therapy Study Investigators. Intensity of continuous renalreplacement therapy in critically ill patients. N. Engl. J. Med. 361, 1627-1638 (2009).

143. Selby, N. M. et al. Defining the cause of death in hospitalised patients with acute kidney injury. PLOS ONE 7, e48580 (2012).

144. Bell, M. et al. Continuous renal replacement therapy is associated with less chronic renal failure than intermittent haemodialysis after acute renal failure. Intensive Care Med. $\mathbf{3 3}$, 773-780 (2007)

145. Korkeila, M., Ruokonen, E. \& Takala, J. Costs of care, long-term prognosis and quality of life in patients requiring renal replacement therapy during intensive care. Intensive Care Med. 26 1824-1831 (2000).

146. Silvester, W., Bellomo, R. \& Cole, L. Epidemiology, management, and outcome of severe acute renal failure of critical illness in Australia. Crit. Care Med. 29, 1910-1915 (2001).

147. Schmitt, R. et al. Recovery of kidney function after acute kidney injury in the elderly: a systematic review and meta-analysis. Am. J. Kidney Dis. 52, 262-271 (2008).

148. Hsu, C. Y. et al. Nonrecovery of kidney function and death after acute on chronic renal failure. Clin. J. Am. Soc. Nephrol. 4, 891-898 (2009).

149. Chawla, L. S., Amdur, R. L., Amodeo, S., Kimmel, P. L. \& Palant, C. E. The severity of acute kidney injury predicts progression to chronic kidney disease. Kidney Int. 79 , 1361-1369 (2011).

150. Thakar, C. V., Christianson, A., Himmelfarb, J. \& Leonard, A. C. Acute kidney injury episodes and chronic kidney disease risk in diabetes mellitus. Clin. J. Am. Soc. Nephrol. 6, 2567-2572 (2011). 
151. Srisawat, N. et al. Plasma neutrophil gelatinaseassociated lipocalin predicts recovery from acute kidney injury following communityacquired pneumonia. Kidney Int. 80, 545-552 (2011).

152. Sutherland, S. M. et al. Fluid overload and mortality in children receiving continuous renal replacement therapy: the prospective pediatric continuous renal replacement therapy registry. Am. J. Kidney Dis. 55, 316-325 (2009).

153. Heung, M. et al. Fluid overload at initiation of renal replacement therapy is associated with lack of renal recovery in patients with acute kidney injury. Nephrol. Dial. Transplant. 27, 956-961 (2012)

154. Karvellas, C. J. et al. A comparison of early versus late initiation of renal replacement therapy in critically ill patients with acute kidney injury: a systematic review and meta-analysis. Crit. Care 15, R72 (2011).

155. Smith, O. M. et al. Standard versus accelerated initiation of renal replacement therapy in acute kidney injury (STARRT-AKI): study protocol for a randomized controlled trial. Trials 14, 320 (2013).

156. Cartin-Ceba, R. et al. Evaluation of "loss" and "end stage renal disease" after acute kidney injury defined by the risk, injury, failure, loss and ESRD classification in critically ill patients. Intensive Care Med. 35, 2087-2095 (2009).

157. Jacka, M. J., Ivancinova, X. \& Gibney, R. T. Continuous renal replacement therapy improves renal recovery from acute renal failure. Can. J. Anaesth. 52, 327-332 (2005).

158. Lin, Y. F. et al. The 90-day mortality and the subsequent renal recovery in critically ill surgical patients requiring acute renal replacement therapy. Am. J. Surg. 198, 325-332 (2009).

159. Mehta, R. L. et al. A randomized clinical trial of continuous versus intermittent dialysis for acute renal failure. Kidney Int. 60, 1154-1163 (2001).

160. Schneider, A. G. et al. Choice of renal replacement therapy modality and dialysis dependence after acute kidney injury: a systematic review and meta-analysis. Intensive Care Med. 39, 987-997 (2013).

161. Uchino, S. et al. Patient and kidney survival by dialysis modality in critically ill patients with acute kidney injury. Int. J. Artif. Organs 30, 281-292 (2007).

162. Wald, R. et al. The association between renal replacement therapy modality and long-term outcomes among critically ill adults with acute kidney injury: a retrospective cohort study. Crit. Care Med. http://dx.doi.org/10.1097/ CCM.0000000000000042.

163. Coca, S. G., Singanamala, S. \& Parikh, C. R. Chronic kidney disease after acute kidney injury: a systematic review and meta-analysis. Kidney Int. 81, 442-448 (2012).

164. Pannu, N. et al. Association between AKI, recovery of renal function, and long-term outcomes after hospital discharge. Clin. J. Am. Soc. Nephrol. 8, 194-202 (2013).

165. Hamel, M. B. et al. Outcomes and costeffectiveness of initiating dialysis and continuing aggressive care in seriously ill hospitalized adults. SUPPORT Investigators. Study to understand prognoses and preferences for outcomes and risks of treatments. Ann. Intern. Med. 127, 195-202 (1997).

166. Ahlstrom, A., Tallgren, M., Peltonen, S., Rasanen, P. \& Pettila, V. Survival and quality of life of patients requiring acute renal replacement therapy. Intensive Care Med. 31, 1222-1228 (2005).

167. Delannoy, B. et al. Six-month outcome in acute kidney injury requiring renal replacement therapy in the ICU: a multicentre prospective study. Intensive Care Med. 35, 1907-1915 (2009).

168. Hofhuis, J. G., van Stel, H. F., Schrijvers, A. J., Rommes, J. H. \& Spronk, P. E. The effect of acute kidney injury on long-term health-related quality of life: a prospective follow-up study. Crit. Care 17, R17 (2013).

169. Johansen, K. L. et al. Predictors of health utility among 60-day survivors of acute kidney injury in the Veterans Affairs/National Institutes of Health acute renal failure trial network study. Clin. J. Am. Soc. Nephrol. 5, 1366-1372 (2010)

170. Joyce, V. R. et al. Health-related quality of life as a predictor of mortality among survivors of AKI. Clin. J. Am. Soc. Nephrol. 7, 1063-1070 (2012).

171. Morsch, C., Thome, F. S., Balbinotto, A., Guimaraes, J. F. \& Barros, E. G. Health-related quality of life and dialysis dependence in critically ill patient survivors of acute kidney injury. Ren. Fail. 33, 949-956 (2011).

172. Fischer, M. J., Brimhall, B. B., Lezotte, D. C., Glazner, J. E. \& Parikh, C. R. Uncomplicated acute renal failure and hospital resource utilization: a retrospective multicenter analysis. Am. J. Kidney Dis. 46, 1049-1057 (2005).

173. Pan, S. W. et al. Acute kidney injury on ventilator initiation day independently predicts prolonged mechanical ventilation in intensive care unit patients. J. Crit. Care 26, 586-592 (2011).

174. Vieira, J. M. Jr et al. Effect of acute kidney injury on weaning from mechanical ventilation in critically ill patients. Crit. Care Med. 35, 184-191 (2007).

175. Dasta, J. F., Kane-Gill, S. L., Durtschi, A. J., Pathak, D. S. \& Kellum, J. A. Costs and outcomes of acute kidney injury (AKI) following cardiac surgery. Nephrol. Dial. Transplant. 23, 1970-1974 (2008).

176. Elseviers, M. M. et al. Renal replacement therapy is an independent risk factor for mortality in critically ill patients with acute kidney injury. Crit. Care 14, R221 (2010).

177. Vaara, S. T. et al. Association of ICU size and annual case volume of renal replacement therapy patients with mortality. Acta Anaesthesiol. Scand. 56, 1175-1182 (2012).

178. Farese, S., Jakob, S. M., Kalicki, R., Frey, F. J. \& Uehlinger, D. E. Treatment of acute renal failure in the intensive care unit: lower costs by intermittent dialysis than continuous venovenous hemodiafiltration. Artif. Organs 33 , 634-640 (2009).

179. Manns, B. et al. Cost of acute renal failure requiring dialysis in the intensive care unit: clinical and resource implications of renal recovery. Crit. Care Med. 31, 449-455 (2003).

180. Rauf, A. A. et al. Intermittent hemodialysis versus continuous renal replacement therapy for acute renal failure in the intensive care unit: an observational outcomes analysis. J. Intensive Care Med. 23, 195-203 (2008).

181. Srisawat, N. et al. Cost of acute renal replacement therapy in the intensive care unit: results from the beginning and ending supportive therapy for the kidney (BEST Kidney) study. Crit. Care 14, R46 (2010).

182. Berbece, A. N. \& Richardson, R. M. Sustained low-efficiency dialysis in the ICU: cost, anticoagulation, and solute removal. Kidney Int 70, 963-968 (2006).

183. Fieghen, H. E. et al. The hemodynamic tolerability and feasibility of sustained low efficiency dialysis in the management of critically ill patients with acute kidney injury. BMC Nephrol. 11, 32 (2010).

184. Chionh, C. Y., Soni, S. S., Finkelstein, F. O., Ronco, C. \& Cruz, D. N. Use of peritoneal dialysis in AKI: a systematic review. Clin. J. Am. Soc. Nephrol. 8, 1649-1660 (2013).
185. Phu, N. H. et al. Hemofiltration and peritoneal dialysis in infection-associated acute renal failure in Vietnam. N. Engl. J. Med. 347, 895-902 (2002)

186. Bazari, H. Hemofiltration and peritoneal dialysis in infection-associated acute renal failure. N.Engl. J. Med. 348, 858-860 (2003).

187. Daugirdas, J. T. Peritoneal dialysis in acute renal failure-why the bad outcome? N. Engl. J. Med. 347, 933-935 (2002).

188. Gabriel, D. P. et al. High volume peritoneal dialysis for acute renal failure. Perit. Dial. Int. 27 277-282 (2007)

189. Ponce, D., Berbel, M. N., Abrao, J. M., Goes, C. R. \& Balbi, A. L. A randomized clinical trial of high volume peritoneal dialysis versus extended daily hemodialysis for acute kidney injury patients. Int. Urol. Nephrol. 45, 869-878 (2013).

190. Ponce, D., Berbel, M. N., Regina de Goes, C., Almeida, C. T. \& Balbi, A. L. High-volume peritoneal dialysis in acute kidney injury: indications and limitations. Clin. J. Am. Soc. Nephrol. 7, 887-894 (2012).

191. Callegari, J. G. et al. Peritoneal dialysis for acute kidney injury in sub-Saharan Africa: challenges faced and lessons learned at Kilimanjaro Christian Medical Centre. Kidney Int. 81, 331-333 (2012).

192. Laukkanen, A., Emaus, L., Pettila, V. \& Kaukonen, K. M. Five-year cost-utility analysis of acute renal replacement therapy: a societal perspective. Intensive Care Med. 39, 406-413 (2013).

193. Wald, R. et al. Chronic dialysis and death among survivors of acute kidney injury requiring dialysis. JAMA 302, 1179-1185 (2009).

194. Honeycutt, A. A. et al. Medical costs of CKD in the medicare population. J. Am. Soc. Nephrol. 24 1478-1483 (2013).

195. Manns, B. J., Mendelssohn, D. C. \& Taub, K. J. The economics of end-stage renal disease care in Canada: incentives and impact on delivery of care. Int. J. Health Care Finance Econ. 7, 149-169 (2007).

196. Baboolal, K. et al. The cost of renal dialysis in a UK setting - a multicentre study. Nephrol. Dial. Transplant. 23, 1982-1989 (2008).

197. Foley, R. N. \& Collins, A. J. End-stage renal disease in the United States: an update from the United States Renal Data System. J. Am. Soc. Nephrol. 18, 2644-2648 (2007).

198. Blake, C., Codd, M. B., Cassidy, A. \& O'Meara, Y. M. Physical function, employment and quality of life in end-stage renal disease. J. Nephrol. 13, 142-149 (2000).

199. Blake, C. \& O'Meara, Y. M. Subjective and objective physical limitations in high-functioning renal dialysis patients. Nephrol. Dial. Transplant. 19, 3124-3129 (2004).

200. Mammen, C. et al. Long-term risk of CKD in children surviving episodes of acute kidney injury in the intensive care unit: a prospective cohort study. Am. J. Kidney Dis. 59, 523-530 (2012).

201. Tjaden, L., Tong, A., Henning, P., Groothoff, J. \& Craig, J. C. Children's experiences of dialysis: a systematic review of qualitative studies. Arch. Dis. Child. 97, 395-402 (2012).

202. Tong, A. et al. Quality of life of young adults and adolescents with chronic kidney disease. J. Pediatr. 163, 1179-1185 e5 (2013).

203. Forman, D. E. et al. Incidence, predictors at admission, and impact of worsening renal function among patients hospitalized with heart failure. J. Am. Coll. Cardiol. 43, 61-67 (2004).

204. Newsome, B. B. et al. Long-term risk of mortality and end-stage renal disease among the elderly 
after small increases in serum creatinine level during hospitalization for acute myocardial infarction. Arch. Intern. Med. 168, 609-616 (2008).

205. Yegenaga, I. et al. Clinical characteristics of patients developing ARF due to sepsis/systemic inflammatory response syndrome: results of a prospective study. Am. J. Kidney Dis. 43, 817-824 (2004).

206. Oppert, M. et al. Acute renal failure in patients with severe sepsis and septic shocka significant independent risk factor for mortality: results from the German prevalence study. Nephrol. Dial. Transplant. 23, 904-909 (2007).

207. Gettings, L. G., Reynolds, H. N. \& Scalea, T. Outcome in post-traumatic acute renal failure when continuous renal replacement therapy is applied early vs. late. Intensive Care Med. 25, 805-813 (1999).

208. Van Biesen, W. et al. Relationship between fluid status and its management on acute renal failure (ARF) in intensive care unit (ICU) patients with sepsis: a prospective analysis. J. Nephrol. 18, 54-60 (2005).

209. Maitland, K. et al. Mortality after fluid bolus in African children with severe infection. N. Engl. J. Med. 364, 2483-2495 (2011).

210. Gattas, D. J. et al. Fluid resuscitation with $6 \%$ hydroxyethyl starch $(130 / 0.4)$ in acutely ill patients: an updated systematic review and meta-analysis. Anesth. Analg. 114, 159-169 (2012).

211. Zarychanski, R. et al. Association of hydroxyethyl starch administration with mortality and acute kidney injury in critically ill patients requiring volume resuscitation: a systematic review and meta-analysis. JAMA 309, 678-688 (2013).

212. O'Malley, C. M. et al. A randomized, double-blind comparison of lactated Ringer's solution and $0.9 \% \mathrm{NaCl}$ during renal transplantation. Anesth. Analg. 100, 1518-1524 (2005).

213. Radaelli, G. et al. The use of inhibitors of angiotensin-converting enzyme and its relation to events in the postoperative period of CABG Rev. Bras. Cir. Cardiovasc. 26, 373-379 (2011).

214. Centers for Disease Control and Prevention. Acute kidney injury associated with synthetic cannabinoid use-multiple states, 2012. MMWR Morb. Mortal. Wkly Rep. 62, 93-98 (2013).

215. Martinelli, S. M. et al. Trends in cardiac surgeryassociated acute renal failure in the United States: a disproportionate increase after heart transplantation. Ren. Fail. 31, 633-640 (2009).

Acknowledgements

S. M. Bagshaw holds a Canada Research Chair in Critical Care Nephrology and his research is supported by a Clinical Investigator Award from Alberta Innovates-Health Solutions.

Author contributions

Both authors researched the data for the article, contributed to discussions of the content, wrote the article and reviewed and edited the manuscript before submission. 